\title{
Influence of the reinforcement corrosion on the bending moment capacity of reinforced concrete beams: a structural reliability approach
}

\section{Influência da corrosão da armadura na capacidade resistente à flexão de vigas em concreto armado: uma abordagem via teoria da confiabilidade estrutural}
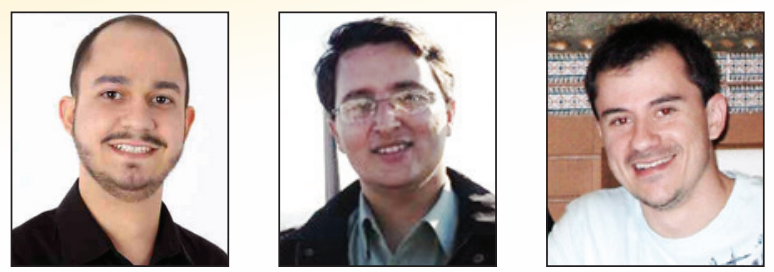

E. A. P. LIBERATI a elysonpl@usp.br

E. D. LEONEL a edleonel@sc.usp.br C. G. NOGUEIRA a gorlanog@sc.usp.br

\begin{abstract}
Reinforced concrete structures are, certainly, one of the most used types of structure around world. When it is located in non-aggressive environments, it respects, in general, the structural life predicted. Unless the structure be used improperly. However, the durability of these structures is strongly connected to degradation processes whose origin is environmental and/or functional. Among these processes, it is worth to mention those related to corrosion of reinforcements. The reinforcement's corrosion is directly related to the durability and safety of concrete structures. Moreover, the chlorides diffusion is recognized as one of major factors that triggers the corrosion. Therefore, at modelling accurately the chloride diffusion, the corrosion of reinforcements can be better evaluated. Consequently, design criteria can be more realistically proposed in order to assure safety and economy into reinforced concrete structures. Due to the inherent randomness present on chloride diffusion and corrosion, these phenomena can only be properly modelled considering probabilistic approaches. In this paper, the durability of a beam designed using the criteria proposed by ABNT NBR 6118:2003 [1] is assessed using probabilistic approaches. The corrosion time initiation is determined using Fick's diffusion law whereas Faraday's corrosion laws are adopted to model the steel loss. The probability of structural failure is determined using Monte Carlo simulation. The mentioned beam is analysed considering different failure scenarios in order to study the influence of water/cement ratio and environmental aggressiveness on the probability of failure. Based on these results, some remarks are performed considering NBR recommendations and the real probability of failure.
\end{abstract}

Keywords: corrosion of reinforcement, reinforced concrete, Fick's second law, Faradays's laws.

\section{Resumo}

As estruturas de concreto armado estão certamente entre as mais utilizadas no mundo da construção civil moderna. Quando tais estruturas estão localizadas em ambientes não agressivos, elas respeitam, em geral, a vida útil para a qual foram projetadas, a menos, evidentemente, que sejam utilizadas de maneira imprópria, violando as funções para as quais foram projetadas. No entanto, a durabilidade destas estruturas está fortemente vinculada a processos de degradação de origem ambiental, que ocorrem em ambientes considerados agressivos. Dentre estes processos de degradação, destacam-se aqueles que desencadeiam a corrosão das armaduras. Dessa forma, a durabilidade está diretamente associada à corrosão das armaduras, que por sua vez, tem como um dos fatores de maior importância, a difusão de íons cloreto como agente desencadeador do processo corrosivo. Assim, efetuando a modelagem precisa deste fenômeno, a corrosão das armaduras pode ser mais bem avaliada e, consequentemente, critérios mais adequados podem ser propostos para proteger o aço dentro do elemento de concreto, garantindo maior segurança estrutural e, portanto, durabilidade da obra. Neste trabalho, os procedimentos descritos pela ABNT NBR 6118:2003 [1] para o dimensionamento de vigas em concreto armado são avaliados por meio de análises probabilísticas. O tempo de início da corrosão das armaduras via penetração de íons cloreto também é analisado a partir do cálculo de probabilidades de ocorrência desse estado limite. Por fim, as leis de Fick e Faraday são utilizadas para a análise da perda de seção transversal de armaduras do elemento estrutural em estudo, submetido à penetração de íons cloreto ao longo do tempo. Para a determinação das probabilidades de falha, o método de simulação de Monte Carlo é utilizado. São apresentados alguns exemplos que mostram a direta influência do fator água/cimento e do ambiente agressivo ao qual o elemento estrutural está inserido na avaliação final probabilidade de falha.

Palavras-chave: corrosão de armaduras, concreto armado, segunda lei de Fick, leis de Faraday. 


\section{Introduction}

Concrete properties, such as versatility in the design of complex architectural geometries, competitive cost when compared to other structural materials and suitable mechanical properties for a wide range of structural requirements, all enhanced with the addition of steel for structural ductility and tensile resistance, make reinforced concrete the most used construction material in the world since the 1950s [2]. Construction techniques and mathematical models for the design of reinforced concrete structures are currently well developed and consolidated in the context of modern engineering. Although safety, economic and functionality requirements are considered during the design process, structural durability has frequently been neglected. The latest review of the Brazilian design code, ABNT NBR 6118 [1], which addresses the design and construction of reinforced and pre-stressed concrete structures, provided significant improvements to accurately consider durability. The inclusion of environmental aggressiveness classes and the correlation with the quality of concrete, the consideration of limits for water/cement ratios and compressive resistance, the improvement on concrete cover values and on the control of concrete cracking reflect the importance and priority of concrete structural durability in actual engineering applications [3].

According to [3], the following factors are primarily responsible for pathological structural manifestations: deficiencies in design, inadequate concrete cover thickness, inadequate specifications for the concrete and constituent materials, inefficient construction processes, inefficient maintenance procedures and the effects of an aggressive environment at the structure's location. Among these factors, environmental aggressiveness cannot be manipulated and modified by human intervention. Environmental aggressiveness is more severe in coastal zones and industrial neighbourhoods, which are classified as classes IV and III, respectively, by ABNT NBR 6118:2003 [1].

Reinforcement corrosion directly affects the durability of reinforced concrete structures. The diffusion of chloride is recognised as one of most important triggers of the corrosion process [4]. The high costs associated with steel loss, structural material mechanical degradation and repair, the loss of structural stability and the recurrence of these problems make the corrosion of reinforcements the principal pathological manifestation in reinforced concrete structures [5].

The corrosion of reinforcements leads to an expansive reaction that causes concrete cracking. Consequently, the concrete porosity increases [6]. A loss of steel is also observed, which leads to the decrease of both the cross-sectional area of the reinforcing bars and the bending and shear structural resistances. Therefore, reinforcement corrosion directly affects the safety of structures.

In general, the mechanical degradation process of reinforced concrete structures resulting from reinforcement corrosion can be divided into two stages: initiation and propagation. During the initiation period, chlorides penetrate into the concrete cover by the diffusion mechanism. Over time, the chloride concentration grows until a threshold value is reached, leading to reinforcement depassivation and, consequently, the start of corrosion. The propagation period includes the development of corrosion, i.e., the period in which the reduction of steel is observed. The propagation period is relatively short when compared to the initiation period. Therefore, the process of chloride diffusion into concrete pores (the initiation period) is often used to indicate the durability and service life of reinforced concrete structures in the framework of reinforcement corrosion [7, 8]. Thus, by modelling the chloride diffusion phenomenon, from exterior surface to concrete cover, and determining the chloride concentration growth along the concrete cover over time, the corrosion of reinforcements and concrete damage because of corrosive reactions can be efficiently evaluated. These last two processes begin when a threshold level of chloride concentration is reached near the reinforcements [9-11].

The chloride ingress is controlled by complex interactions between physical and chemical mechanisms in which several sources of uncertainties are observed. This phenomenon is often simplified, without significant loss of accuracy, to a process controlled only by diffusion. Therefore, this problem can be modelled considering the second Fick's law for diffusion, which requires the following assumptions: the apparent diffusion coefficient is constant over time and homogeneous in space, the concentration of chloride in the environment is constant, and the concrete is assumed to be fully saturated. Uncertainties surrounding material properties, environmental conditions and the mathematical/numerical models that simulate corrosion exist. These uncertainties make the modelling of this problem a difficult task. Therefore, purely deterministic approaches cannot properly assess the durability of reinforced concrete structures subject to the corrosion process [12].

After the reliability theory was first applied to structural analyses in the 1980s, the modelling of structural phenomena considering uncertainties became attractive. This approach allows the inclusion of uncertainties in several analyses in a consistent theoretical manner through statistical associations [13]. Therefore, the combination of a mechanical model based on Fick's laws and reliability algorithms allows for a more consistent, comprehensive and reliable framework than a purely deterministic approach. Such models are robust, for instance, in estimating the probability of corrosion start, supporting several maintenance and repair procedures.

Several studies have dealt with the problem of reinforcement corrosion affecting only the reinforcement cross-sectional area without considering the concrete damage effect [10-12]. These methodologies can be considered as preliminary because they do not consider the consequences of corrosion on the concrete mechanical behaviour. However, these approaches may be used in determining pre-design goals.

In this paper, a study on the bending structural resistance loss in reinforced concrete beams subjected to chloride penetration and reinforcement corrosion is performed. The analyses are conducted using a reliability approach, which involves the combination of Fick's laws, empirical laws for corrosion evolution and the bending resistance equations given by [1]. The primary goal is to assess the probability of corrosion initiation and the increase in this probability when the reinforcement corrosion begins. Therefore, this study aims to contribute to the structural durability field, using equilibrium equations defined by a standard code [1], and assess structural safety when mechanical degradation processes are present.

\section{Simple bending case}

The equations that express the equilibrium conditions for bended beams, considering single and double layer of reinforcement, are presented in this section. These formulations are based on the following assumptions [1]: 
a) the structural cross-sections remain plane until structural failure and normal strains along the cross-section are linearly distributed;

b) the concrete and reinforcement have perfect adherence. Bondslip behaviour is not considered;

c) the resistance contribution of tensiled concrete is not considered;

d) the reduction in failure conditions for concrete not fully in compression is equal to $3,5 \%$ (domains 3,4 and $4 a$ );

e) the maximum elongation allowed for tensiled reinforcement is $10 \%$. This value is defined to prevent excessive plastic strains;

f) the distribution of compressive stresses in the concrete follows a parabolic-rectangle stress-strain diagram. However, a simplified rectangular diagram is used, which states that the height of the reinforced concrete is $y=0,8 x$. This last diagram assumes that height $\mathrm{y}$ is subjected to a constant compressive stress equal to $\sigma_{c d}$

The strains in the reinforced concrete components subjected to bending belong to domains 2, 3 and 4, which are defined by [1]. Based on these assumptions, the neutral surface is contained within the structural cross-section. Therefore, the cross-section area includes an area in compression and a complementary area in tension.

\subsection{Design of reinforced concrete considering single and double layer reinforcement}

The structural cross-sections with a single layer of reinforcement are cross-sections in which the reinforcement layers are located at the tensile face, whereas cross-sections with a double layer of reinforcement are those in which reinforcement layers are positioned at both compressive and tensile faces. The formulation adopted in this study assumes that reinforcements are positioned in one layer, at either tensiled, compressed or both faces; even in practical applications, more than one layer may be possible. Figure 1 shows the nomenclature used in the adopted formulation, states the strain distribution and the simplified rectangular diagram for stress distribution on concrete, with height $y=0.8 x$ and the equivalent forces $\left(R_{C}, R_{S}\right.$ and $\left.R_{S}^{\prime}\right)$ associated with the rectangular structural crosssection considering double layer of reinforcement $\left(A_{S}\right.$ and $\left.A_{S}^{\prime}\right)$. The cross-section width is defined as $b$ and the effective depth as $d$. Thus, considering Figure 1, the equilibrium of forces and bending moments can be written as follows:

$$
R_{c}+R_{s}^{\prime}-R_{s}=0 \rightarrow 0.68 b d \beta_{x} f_{c d}+A_{s}^{\prime} \sigma_{s}^{\prime}-A_{s} \sigma_{s}=0
$$

$$
M_{d}=\gamma_{f} M_{a}=R_{c}(d-y / 2)+R_{s}^{\prime}\left(d-d^{\prime}\right)
$$

Using the definitions presented in Figure 1, Eq. (2) can be rewritten as follows:

$$
M_{d}=0.68 b d^{2} \beta_{x} f_{c d}\left(1-0.4 \beta_{x}\right)+A_{s}^{\prime} \sigma_{s}^{\prime}\left(d-d^{\prime}\right)
$$

If the single layer of reinforcement case is considered, Eq. (3) can be simplified because $A_{S}^{\prime}$ is null. Then, Eq. (1) and Eq. (3) are rewritten, for the single reinforcement layer, as follows:

$$
0.68 b d \beta_{x} f_{c d}-A_{s} \sigma_{s}=0
$$

$$
M_{d}=0.68 b d^{2} \beta_{x} f_{c d}\left(1-0.4 \beta_{x}\right)
$$

\section{Figure 1 - Pure bending case in rectangular cross-sections considering single and double layer of reinforcements}

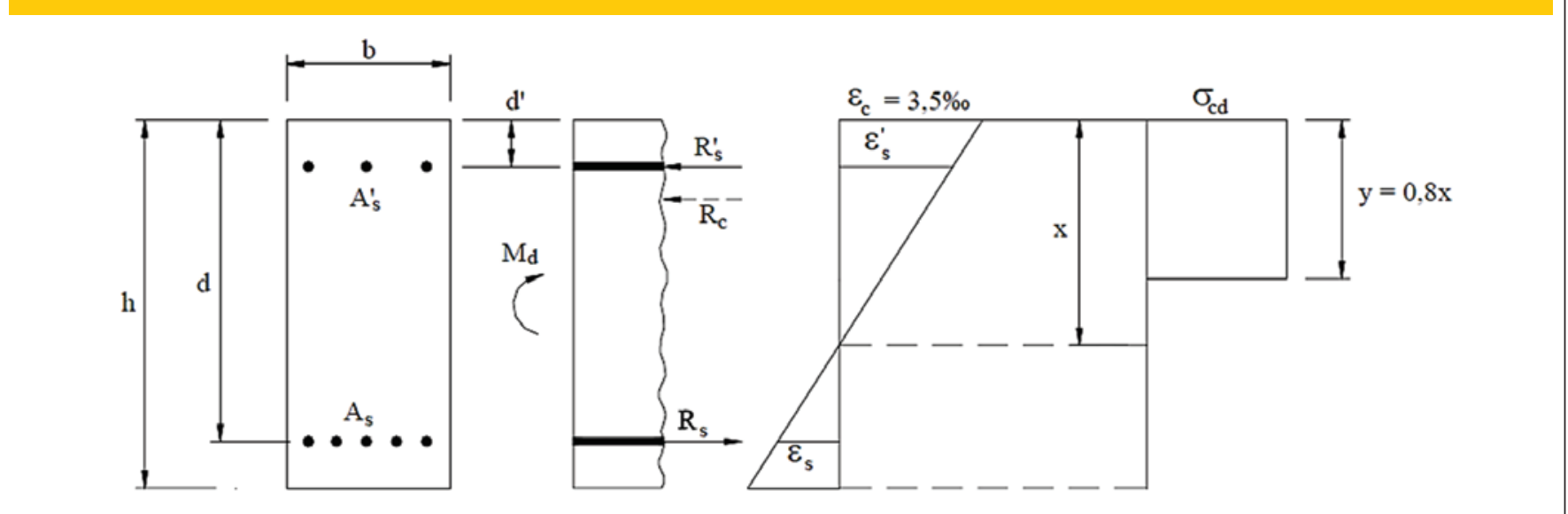


If a simple bended beam subjected to a uniformly distributed load is considered, the maximum exterior bending moment is given by:

$$
M_{a}=\frac{P L^{2}}{8} \quad(k N . m)
$$

where the external load $P$ is composed of:

$$
P=G+Q \quad(k N / m)
$$

where $G$ is the permanent load and $Q$ is the accidental load.

Based on the reinforcement area and cross-section dimensions, the resistance bending moment of a beam is calculated as follows:

$$
\begin{aligned}
& M_{r}=0.408 b d^{2} f_{c d} \beta_{x}^{2}+A_{s} \sigma_{s} d\left(1-\beta_{x}\right)+ \\
& A_{s}^{\prime} \sigma_{s}^{\prime}\left(d \beta_{x}-d^{\prime}\right)(k N m)
\end{aligned}
$$

The structural resistance in terms of bending moment is given by Eq. (8). This equation will be adopted to evaluate the structural resistance over time to assess the probability of structural failure because of reinforcement corrosion.

\section{Fick's diffusion laws}

In 1885, Fick was the first researcher to describe the phenomenon of diffusion through an adaptation of Fourier's empirical heat conduction equations [14]. The transport phenomenon associated with the movement of chlorides along structures exposed to aggressive environments is primarily attributed to the diffusion of chloride ions into concrete pores under a concentration gradient. The coefficient of chloride diffusion, which depends on the pore structure of the concrete, characterises this flow under a given external concentration of chloride. This parameter is a characteristic of hardened concrete. To simulate the chloride ingress and its transport into concrete pores, Fick's diffusion laws [15] have been widely considered acceptable models. Fick's laws for diffusion are applicable for homogeneous, isotropic and inert materials [16]. The mechanical properties related to the diffusion process are assumed identical along all directions and kept constants over time. Because concrete is well known as a heterogeneous, anisotropic and chemically reactive (continued hydration and microcracking process) material, these hypotheses are not completely satisfied. However, the methods commonly adopted for chloride transportation modelling in concrete consider this process to be governed by ionic diffusion only. The concrete cover is assumed to be completely saturated. Therefore, the hypotheses of Fick's laws are acceptable for the chloride ingress modelling. In this case, the material is assumed to be completely saturated, with unidirectional chloride flux, i.e., from the exterior surface into the concrete depth. When chloride diffuses into concrete, a change in chloride concentration, $C$, occurs at time, $t$, at every point, $x$, of the concrete, i.e., it is a non-steady state of diffusion. To simplify the analysis, the diffusion problem is considered one-dimensional. Numerous chloride ingress engineering problems, such as those discussed in this paper, can be solved using this simplification. Figure 2 shows a typical profile of chloride penetration into the concrete cover.

The assumption of Fick's diffusion theory is that the transport of chloride into concrete through a unit section area of concrete per unit of time (the flux $F$ ) is proportional to the chloride concentration gradient normal to the section. Then:

$F=-D_{c} \frac{\partial C}{\partial x}$

The negative sign in the equation above signifies that the diffusion of chlorides occurs in the direction opposite the increasing concentration of chlorides. The constant of proportionality $D_{c}$, presented in Eq. (9), is called the chloride diffusion coefficient. In general, $D_{c}$ is not constant but depends on many parameters, including the time diffusion occurred, location in the concrete and composition of concrete. If the chloride diffusion coefficient is constant, Eq. (9) is usually referred to as Fick's first diffusion law. If this is not the case, the relation is referred to as Fick's first general diffusion law. This simple relation should not always be applied, particularly when the diffusion process may be irreversible or has a history of dependence. In such cases, Fick's diffusion laws are not valid and the diffusion process is considered anomalous. However, nonobservation so far indicates that the chloride diffusion into concrete pores should be characterised as an anomalous diffusion. Fick's second law can be derived considering the mass balance principle. Therefore:

$$
\frac{\partial C}{\partial t}=\frac{\partial}{\partial x}\left(-D_{c} \frac{\partial C}{\partial x}\right)
$$

To apply Fick's second diffusion law in this form, for concrete exposed to chloride over a long period, the variation of the chloride

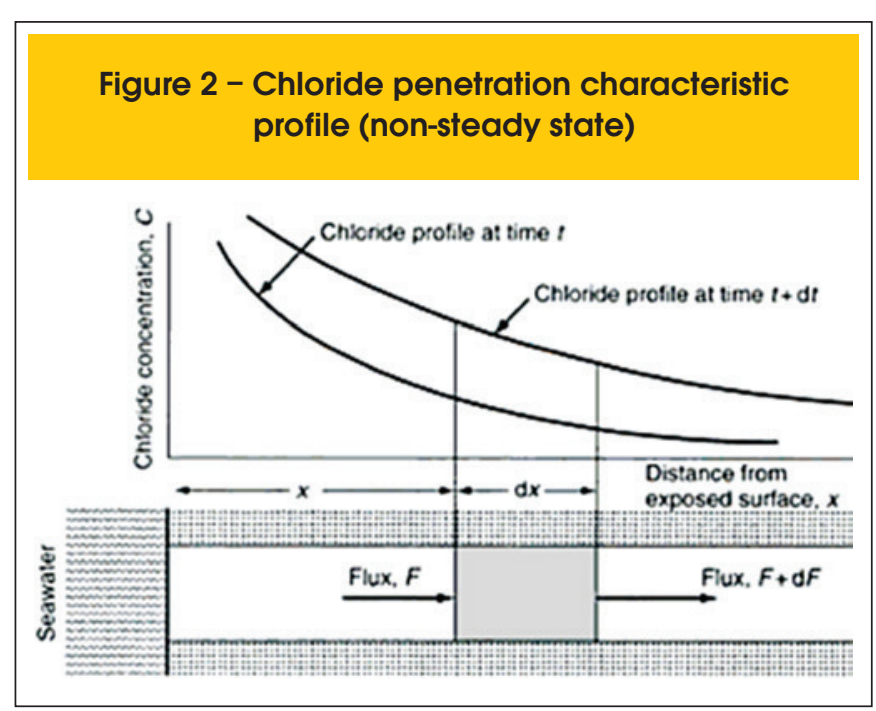


diffusion coefficient over time, $t$, is required. If only a few observations exist in a specific case, it is possible to estimate the upper and lower boundary for the variation of $D$ over time. Despite this dependence, a unique case can be considered when the chloride diffusion coefficient is independent of location, $x$, time, $t$ and chloride concentration, $C$. In this case, Fick's second law can be written in this simple form:

$$
\frac{\partial C}{\partial t}=D_{0} \frac{\partial^{2} C}{\partial x^{2}}
$$

where $D_{0}$ is the constant coefficient of diffusion

The solution of the differential equation presented above, for a semi-infinite domain with a uniform concentration at the structural surface, is given by:

$$
C(x, t)=C_{0} \operatorname{erfc}\left[\frac{x}{2 \sqrt{D_{0} t}}\right]
$$

where $C_{0}$ is the chloride concentration at the structural surface, assumed constant over time; and erfc is the complementary error function.

In a physical sense, field conditions deviate significantly from the assumptions implicit in Fick's laws. For instance, the concrete cover is not always saturated with water, and chloride ions penetrate concrete by diffusion and advection provided by the penetrating moisture front. Concrete is not homogeneous because of the presence of microcracking and interconnected pores, and the diffusion coefficient will change over time as hydration proceeds. Hence, Fick's laws are not the ideal model for this phenomenon. However, Fick's laws are often used because the diffusion equation provides the best approximation of laboratory or field data in many cases. Predictions using this approach are valid only if best-fit parameter values are applied to structures with similar material, environmental and field conditions. It is preferable, in using this approach, that concentrations are given in terms of water-soluble chloride because it is generally accepted that corrosion is influenced by the free chloride concentration present in the concrete pore solution [17].

In this paper, Eq. (12) is used to evaluate the time at which the corrosion process starts. After the corrosion initiation phase, the reinforcement areas deteriorate using the relations that will be presented in next section.

If the threshold chloride concentration value at the steel reinforcements is known, then the time for steel depassivation and, consequently, the time for corrosion initiation can be determined. In this case, the time for corrosion initiation can be explicitly obtained as follows:

$$
t_{R}=\frac{1}{D_{0}}\left\{\frac{x}{2 e r f c^{-1}\left[C(x, t) / C_{0}\right]}\right\}^{2}
$$

\section{Reinforcement corrosion modelling}

Corrosion can be defined as the mechanical degradation process that occurs in metallic materials as a result of chemical or electrochemical actions. This process can also be associated with external loads [18]. In corrosion of metallic materials, the material is converted into a non-metallic material. When corrosion occurs, the metal loses some essential properties such as mechanical resistance, elasticity and ductility [19].

The corrosion process can be classified as chemical or electrochemical. The first type of corrosion, also known as dry corrosion or simple oxidation, occurs by a gas-metal reaction, which produces an oxide film. It is a slow process and does not cause substantial deterioration of the metal surfaces, except in the presence of extremely aggressive gases. Electrochemical corrosion produces effective material damage because this type of corrosion involves the conduction of electrons among different regions of the metal [19].

According to the classical corrosion model proposed by [17], the reinforcement corrosion phenomenon occurs in two distinct stages: initiation and propagation. The initiation period is limited by the time required for reinforcement depassivation resulting from the penetration of chlorides. The propagation period includes that time when the cross-sectional area of the reinforcement steel is lost. Therefore, in this final corrosion phase, maintenance and repair are mandatory to avoid structural failure resulting from a decrease in structural resistance. Figure 3 shows the evolution of the crosssectional diameter of the reinforcements as a function of time, where the initiation and propagation periods are clearly defined.

The amount of reinforcement corrosion during the propagation period will depend on environmental moisture and the amount of available oxygen. These two parameters significantly influence the cathodic process and the concrete resistivity. Temperature also catalyses the corrosion process.

\subsection{Modelling of reinforcement cross-section area loss}

Mathematical approaches for modelling the propagation period of corrosion are not often available in literature because many

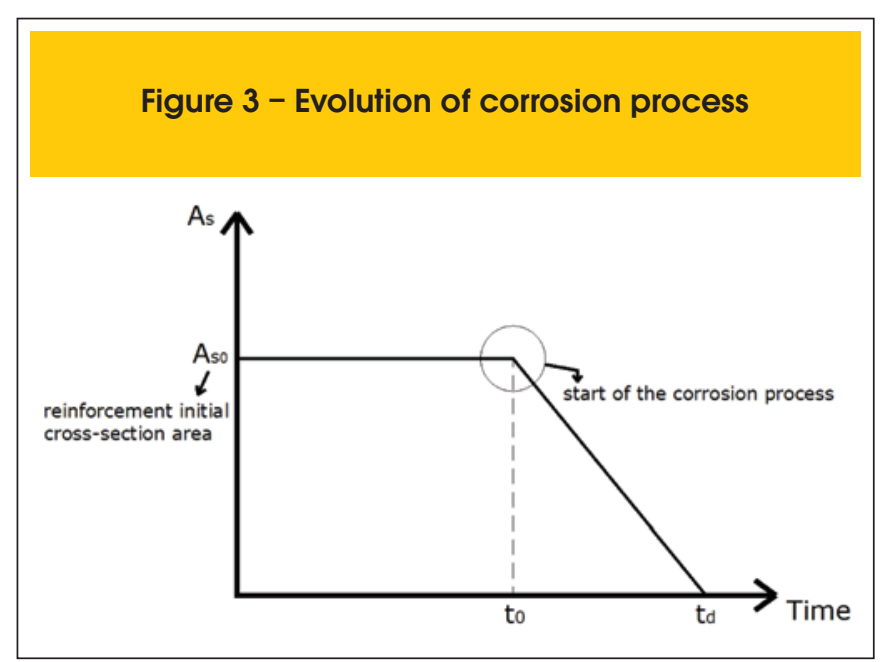


Figure 4 - Uniform corrosion model

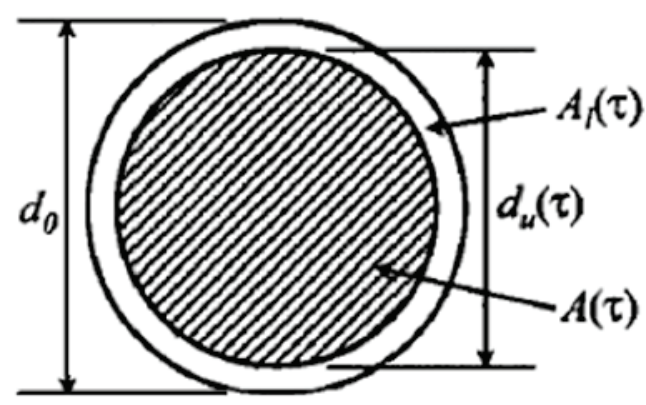

researchers consider the initiation period as the structural lifetime. However, the reduction in steel is consistently represented by the models presented in $[4,20]$. This model was determined empirically, considering a tropical climate.

In this study, the steel loss is evaluated using the model presented in $[4,20]$, which assumes that steel corrodes uniformly along its perimeter, as presented in Figure 4. For this model, the diameter of corroded reinforcements is determined as follows:

$$
d(t)=\left[\begin{array}{lll}
d_{\text {initial }} & \text { if } & t \leq t_{0} \\
d_{\text {initial }}-0.0232 i_{\text {CORR }}\left(t-t_{0}\right) & \text { if } & t>t_{0}
\end{array}\right]
$$

where $d_{\text {initial }}$ is the reinforcement diameter before depassivation in $\mathrm{mm} ; t_{0}$ represents the time of corrosion initiation in years; and $i_{\text {corr }}$ indicates the corrosion ratio given by $\mu \mathrm{A} / \mathrm{cm}^{2}$.

The corrosion ratio is calculated using the expression presented in [4], which was determined empirically.

$$
i_{C O R R}=\frac{37,8(1-w / c)^{-1,64}}{c v r}\left(\mu \mathrm{A} / \mathrm{cm}^{2}\right)
$$

where $w / c$ indicates the water/cement ratio and $c v r$ represents the concrete cover thickness in $\mathrm{cm}$.

\section{Structural reliability theory and analysis methods}

\subsection{General concepts}

The goal of the reliability analysis is to calculate the probability of failure given a specific failure scenario, known as the limit state. Reliability, $R$, and probability of failure Pf are complementary concepts, and $\mathrm{R}=1$ - Pf.

The first step in the reliability assessment is to identify the basic set of random variables $X=\left[x_{1}, x_{2}, \ldots, x_{n}\right]^{T}$ for which uncertainties must be considered. For all of these variables, probability distributions are assigned to model the randomness. These probability distributions can be defined by physical observations, statistical studies, laboratory analysis and expert opinion. The number of random variables is an important parameter to determine the computing time utilised during the reliability analysis. To reduce the size of the random variable space, it is strongly recommended that all variables whose uncertainties minimally affect the probability of failure should be considered deterministic.

The second step consists of defining a number of potentially critical failure modes. For each mode, a limit state function $G(X)$ separates the space into the following two regions as described in Figure 5: the safe domain, where $G(X)>0$, and the failure domain where $G(X)<0$. The boundary between these two domains is defined by $G(X)=0$, known as the limit state itself. An explicit expression for the limit state function is not often possible. In this study, the limit state functions are those presented in Eq. (5), Eq. (8) and Eq. (13).

The probability of failure is evaluated by integrating the joint density function over the failure domain [21]:

$$
P_{f}=\int_{G \leq 0} f_{X}\left(x_{1}, x_{2}, \ldots, x_{n}\right) d x_{1}, d x_{2}, \cdots d x_{n}
$$

where $f_{X}\left(x_{1}, x_{2}, \ldots, x_{n}\right)$ is the joint density function of the variables $X$. The evaluation of the above integration is impossible in practice because the joint density function does not have an explicit form; alternative procedures have thus been developed based on the concept of reliability index, $\beta$ [22]. This parameter is defined by the distance between the mean point and the failure point placed at the limit state function $G(X)=0$ in the normalised space of random variables. The reliability index allows the calculation of the probability of failure as follows:

$$
P_{f}=\Phi(-\beta)
$$

Figure 5 - Failure and safety domains considering two random variables

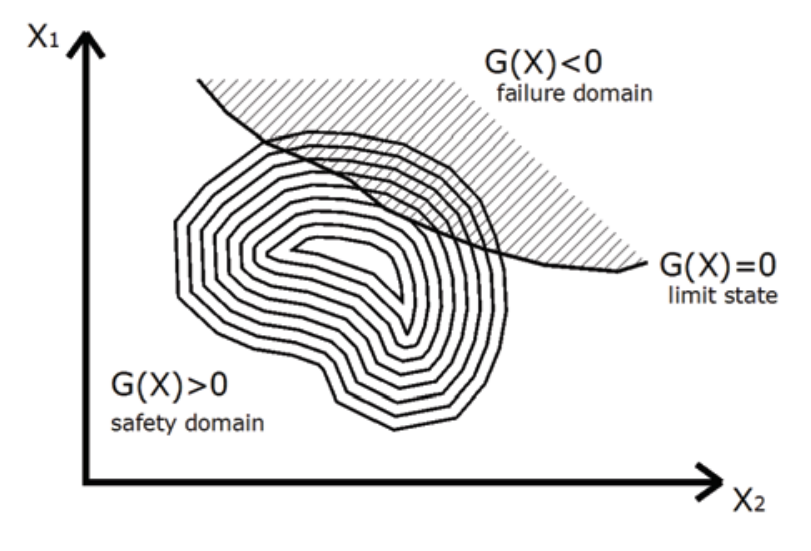


where $\Phi(\cdot)$ is the standard Gaussian cumulated distribution function. There are alternative procedures available to calculate probabilities of failures that are based on numerical simulation techniques. The Monte Carlo simulation is adopted in this study to determine the probability of structural failure. This approach will be discussed in the following section.

\subsection{Monte Carlo simulation}

Monte Carlo methods are numerical simulation procedures widely used in reliability problems. In this method, a sampling of random variables is used to construct a set of values to describe the failure and safe spaces to calculate Eq. (16). The sampling is constructed based on the statistical distribution assigned for each random variable considered in the problem. Because this method addresses the simulation of the limit state function, the larger the sample, the more accurate the spaces' description and the probability of failure calculation.

The kernel of this method consists of the construction of a sampling for the random variables involved in the problem, as described in Figure 6 . The probability of failure is calculated, using a Monte Carlo simulation, using the following equation:

$$
P_{f}=\int_{G \leq 0} f_{X}\left(x_{i}\right) d x_{i}=\int_{G \leq 0} I\left(x_{i}\right) f_{X}\left(x_{i}\right) d x_{i}=E\left[I\left(x_{i}\right)\right]
$$

The function $I\left(x_{i}\right)$ can be estimated as follows:

$$
I\left(x_{i}\right)=\left\{\begin{array}{l}
1 \rightarrow G \leq 0 \\
0 \rightarrow G>0
\end{array}\right.
$$

By simulating the limit state function for a convenient number of samples, the mean value of $I\left(x_{i}\right)$ will be an estimator for the probability of failure:

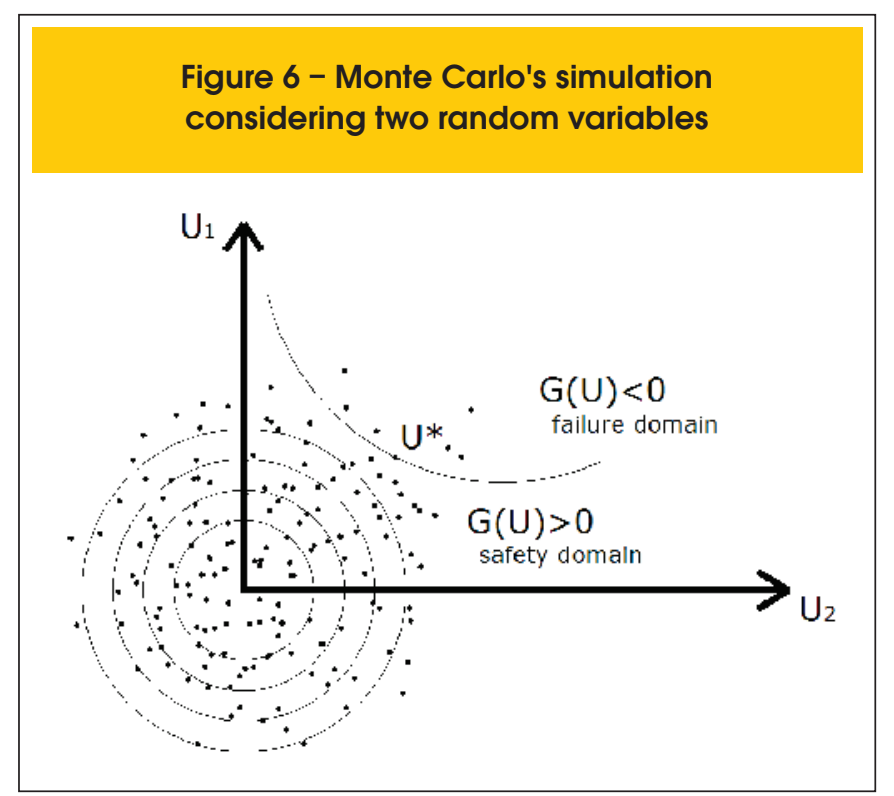

$$
\bar{P}_{f}=E\left[I\left(x_{i}\right)\right]=\frac{1}{N} \sum_{i=1}^{N} I\left(x_{i}\right)
$$

The disadvantage of this method is the large number of simulations required to accurately compute the probability of failure. Normally, to accurately estimate a probability of failure of $10^{-n}$, the number of simulations must be greater than $10^{n+2}$ or $10^{n+3}$. Thus, for engineering structures, when the probability of failure is between $10^{-3}$ and $10^{-6}, 10^{5}$ to $10^{9}$ realisations of the limit state function are required. When complex numerical mechanical models are involved, requiring significant computational times, this method may not be reliable. However, theoretically, when the number of simulations tends to infinity, the calculated probability of failure tends to its real value. Other details about the Monte Carlo simulation can be found in [23].

\section{Analysis methodology}

The structural element analysed in this study is a simple supported bended beam constructed of reinforced concrete and subjected to a uniform distributed load, as shown in Figure 7. The computational codes developed for the design of the analysed beam and all reliability approaches considered were written in FORTRAN.

The following deterministic values were adopted for the analyses performed: beam length $(\mathrm{L}): 6.0 \mathrm{~m}$; cross-section width (b): 17.0 $\mathrm{cm}$; beam height (h): $50.0 \mathrm{~cm}$; stirrups diameter: $6.3 \mathrm{~mm}$; structural lifetime $\left(t_{\mathrm{p}}\right): 50$ years; and time assumed for corrosion development $\left(t_{\text {corr }}\right): 30$ years.

Considering the standard procedures described in [1], the first example of this study determines the probability of structural failure considering the beam presented in Figure 7 without corrosion effects. Several values of $\beta_{x}$ are analysed, which are related to the strain domains considered. For the first example, structural failure is observed when the bending moment resulting from an external load is greater than the resistance bending moment of the concrete and steel. The main parameters considered in this reliability analysis are the following:

- Permanent load: G;

Accidental load: Q;

- Resistance of concrete: $f_{c k}$;

Yield resistance of steel: $\sigma_{s}$.

The modelling of the corrosion phenomenon in reinforced concrete structures considers two different stages: initiation and propagation. The initiation period is related to the chloride penetration into

Figure 7 - Structural element considered in this study

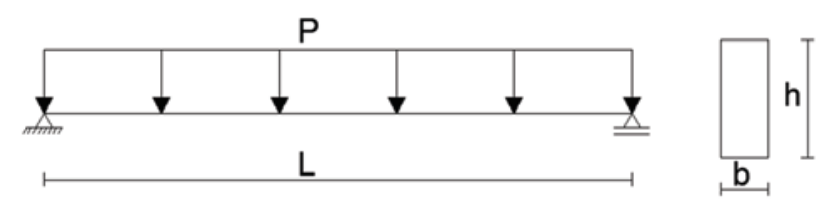


Table 1 - Results of the design of the reinforced concrete beam analyzed

\begin{tabular}{|c|c|c|c|c|}
\hline Variables & $\beta_{x}=0.259$ & $\beta_{x}=0.5$ & $\beta_{x}=0.628$ single reinforcements' layer & $\beta_{x}=0.628$ double reinforcements' layer \\
\hline$d(\mathrm{~cm})$ & 44.12 & 42.50 & 40.87 & 40.87 \\
\hline $\mathrm{d}^{\prime}(\mathrm{cm})$ & - & - & - & 4.26 \\
\hline As $\left(\mathrm{cm}^{2}\right)$ & 7.5 & 12.50 & 15.00 & 17.50 \\
\hline$A^{\prime} s\left(\mathrm{~cm}^{2}\right)$ & - & - & - & 2.50 \\
\hline
\end{tabular}

the concrete pores over time but steel loss does not occur. During this period, the chloride concentration along the structural cover increases. The corrosion process starts when a threshold level of chloride concentration at the steel reinforcements is reached, leading to the loss of passive chemical protection provided by the concrete (depassivation). The second beam example considered in this paper assesses the probability of failure considering the time for corrosion initiation as the failure scenario. Therefore, failure is observed when the chloride concentration surrounding the steel reinforcements reaches the threshold value. The following parameters are considered in this reliability analysis:

- Threshold level of chloride concentration required to begin the corrosion process [4]: $\mathrm{C}(\mathrm{x}, \mathrm{t})$;

- Chloride concentration at the structural surface [10]: $C_{0}$;

- Concrete diffusion coefficient [24]: $\mathrm{D}_{0}$;

- Structural cover thickness [1]: $x$.

According to [4], the chloride concentration at the structural surface depends on the aggressiveness of the environment where the structure is located. The structural cover thickness is determined according to the level of environmental aggressiveness, as described in [1]. The concrete diffusion coefficient, which describes the concrete resistance against chloride ingress, is a function of the water/cement ratio.

In the final beam presented, a probabilistic analysis combines the mechanical model given by [1], Fick's laws and corrosion equations. Therefore, the last application assesses the probability of failure considering the effects of the corrosion process on structural resistance, i.e., the loss of reinforcement area. The reinforced concrete beam is evaluated considering different values of $\beta x$. The parameters considered in this last reliability analysis are identical to those presented above.

The probabilistic analyses considered in this study were performed based on different limit state functions to evaluate the influences of an aggressive environment and the water/cement ratio on the development of corrosion process. In the following examples, the analyses were performed considering two aggressive environ- ments, with four different water/cement ratios for each aggressiveness category. The initial cracks resulting from concrete hardening and creep were not considered.

\section{Results and discussion}

\subsection{Example 1}

In this example, the reinforced concrete beam was designed as follows: $\beta x=0.259 ; \beta x=0.500 ; \beta x=0.628$ for a single layer of reinforcement; and $\beta x=0.628$ for a double layer of reinforcement. Table 1 presents the values used based on this beam design. The Monte Carlo simulation was then used together with the mechanical model, Eq. (6) and Eq. (8), to assess the probability of structural failure.

For the first evaluation of probability of structural failure, the following limit state function was considered:

$$
\mathrm{G}_{1}=\mathrm{M}_{\mathrm{r}}-\mathrm{M}_{\mathrm{a}}
$$

where $M_{r}$ is the resistant bending moment and $M_{a}$ is the bending moment from external loads.

Table 2 presents the random variables considered in this analysis and the statistical properties.

The analyses based on Monte Carlo simulation were performed considering 50,000 samples for each random variable, which produced 50,000 simulations of the limit state function. The relationship between the probability of structural failure and the number of samples can be observed in Figure 8 . In all studied cases, the probability of structural failure tends toward convergence as the number of samples increases. This behaviour is expected because when using a Monte Carlo simulation, the larger the sample adopted, the more accurate the results. Therefore, the sample range

\section{Table 2 - Statistic data for random variables}

\begin{tabular}{cccc} 
Random variable & Mean & Coefficient of variation & Statistic distribution \\
$G$ & $15 \mathrm{kN} / \mathrm{m}$ & $10 \%$ & Normal \\
$Q$ & $5 \mathrm{kN} / \mathrm{m}$ & $20 \%$ & Gumbel \\
$f_{\mathrm{ck}}$ & $25 \mathrm{MPa}$ & $15 \%$ & Normal \\
$\sigma_{\mathrm{s}}$ & $50 \mathrm{kN} / \mathrm{cm}^{2}$ & $10 \%$ & Log-normal \\
\hline
\end{tabular}




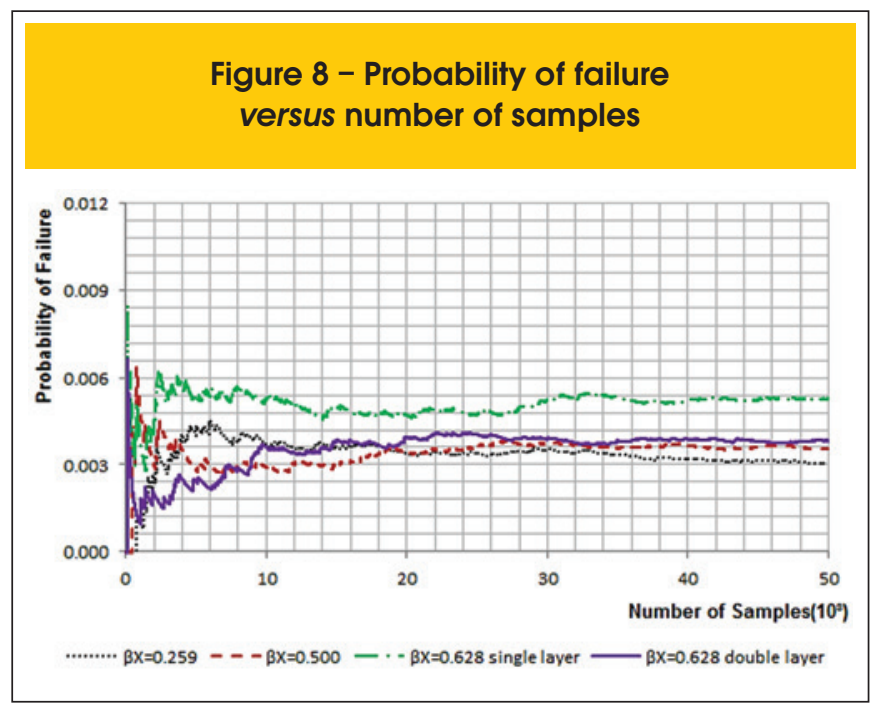

used in this example provides sufficiently accurate results.

Figure 8 also shows that the choice of $\beta x$ values results in different probabilities of structural failure. The calculated probabilities of structural failure are consistent with the safety values recommended by [25], which range from $10^{-3}$ to $10^{-4}$. The use of different positions for the neutral surface, i.e., different design domains, results in different values of probability of failure, even with the use of identical partial safety factors and other design parameter values.

\subsection{Example 2}

This example assessed the probability of failure considering the failure scenario defined as the time for corrosion initiation. The limit state function for this example is defined as follows:

$$
G_{2}=t_{R}-t_{P}
$$

where $t_{R}$ is the time of corrosion initiation calculated using Fick's law and $t_{p}$ is the predicted structural life, considered as 50 years.

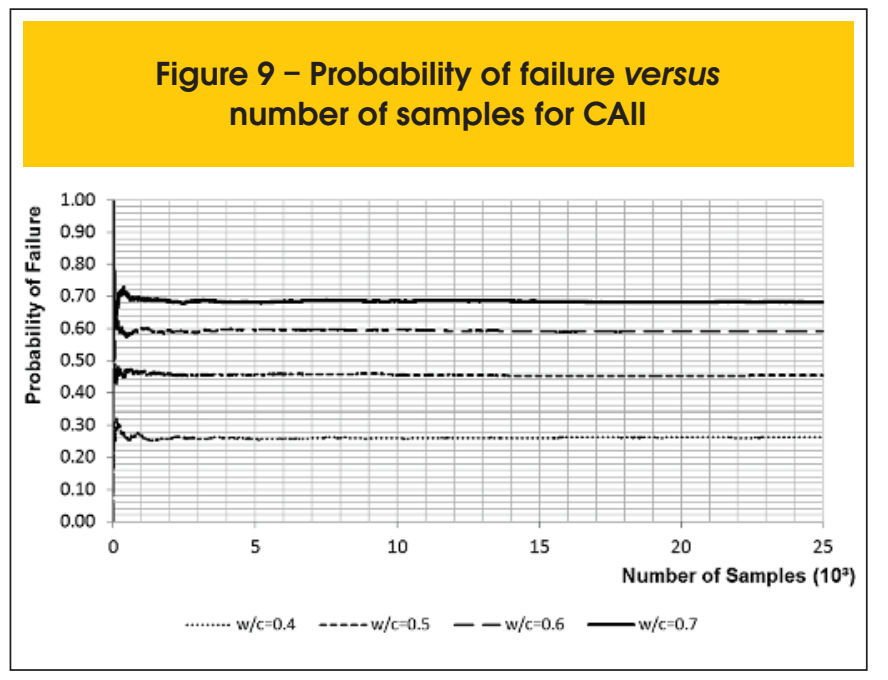

Table 3 presents the random variables considered and the statistical properties.

The concrete diffusion coefficient depends on the water/cement ratio (w/c), used during the concrete production. The chloride concentration at the structural surface and the concrete cover thickness depend on the environmental aggressiveness (CA). In this study, the environmental aggressiveness CA II (urban environment) and CA III (marine environment) were considered. For each $\mathrm{CA}$, the following four $\mathrm{w} / \mathrm{c}$ ratios were considered: $\mathrm{w} / \mathrm{c}=0.4, \mathrm{w} / \mathrm{c}=$ $0.5, w / c=0.6$ and $w / c=0.7$.

In this example, Monte Carlo simulations were performed considering a range sample of 25,000 for each random variable, resulting in 25,000 limit state function simulations. The results of this analysis are shown in Figures 9 and 10.

According to the results presented in these figures, the probability of corrosion initiation converges to the response as the number of samples increases. In Figure 9, a dependence on the probability of failure values and the $w / c$ ratio is observed. When the $w / c$ ratio is 0.70 , the probability of failure is 0.70 . These values were expected because a larger $\mathrm{w} / \mathrm{c}$ ratio indicates a more porous concrete and it is easier for the chloride to penetrate into the structure. This increases the probability of failure.

In addition to the influence of the w/c ratio on the probability of failure, the chloride concentration at the structural surface also has a

Table 3 - Statistic data for random variables

\begin{tabular}{|c|c|c|c|}
\hline Random variable & Mean & Coefficient of variation & Statistic distribution \\
\hline$C(x, t)$ & $0.9 \mathrm{~kg} / \mathrm{m}^{3}$ & $19 \%$ & Uniform (0.6 a 1.2) \\
\hline $\mathrm{C}_{0}$ & $\begin{array}{l}\text { CA II - } 1.15 \mathrm{~kg} / \mathrm{m}^{3} \\
\text { CA III }-2.95 \mathrm{~kg} / \mathrm{m}^{3}\end{array}$ & $\begin{array}{l}50 \% \\
70 \%\end{array}$ & $\begin{array}{l}\text { Log-normal } \\
\text { Log-normal }\end{array}$ \\
\hline$D_{0}$ & $\begin{array}{l}\mathrm{w} / \mathrm{c}=0.4-14.2 \mathrm{~mm}^{2} / \text { year } \\
\mathrm{w} / \mathrm{c}=0.5-41.0 \mathrm{~mm}^{2} / \text { year } \\
\mathrm{w} / \mathrm{c}=0.6-86.4 \mathrm{~mm}^{2} / \text { year } \\
\mathrm{w} / \mathrm{c}=0.7-162.7 \mathrm{~mm}^{2} / \text { year }\end{array}$ & $\begin{array}{l}75 \% \\
75 \% \\
75 \% \\
75 \%\end{array}$ & $\begin{array}{l}\text { Log-normal } \\
\text { Log-normal } \\
\text { Log-normal } \\
\text { Log-normal }\end{array}$ \\
\hline$x$ & $\begin{array}{l}\text { CA II }-30 \mathrm{~mm} \\
\text { CA III }-40 \mathrm{~mm}\end{array}$ & $\begin{array}{l}50 \% \\
50 \%\end{array}$ & $\begin{array}{l}\text { Log-normal } \\
\text { Log-normal }\end{array}$ \\
\hline
\end{tabular}


Influence of the reinforcement corrosion on the bending moment capacity of reinforced concrete beams: a structural reliability approach

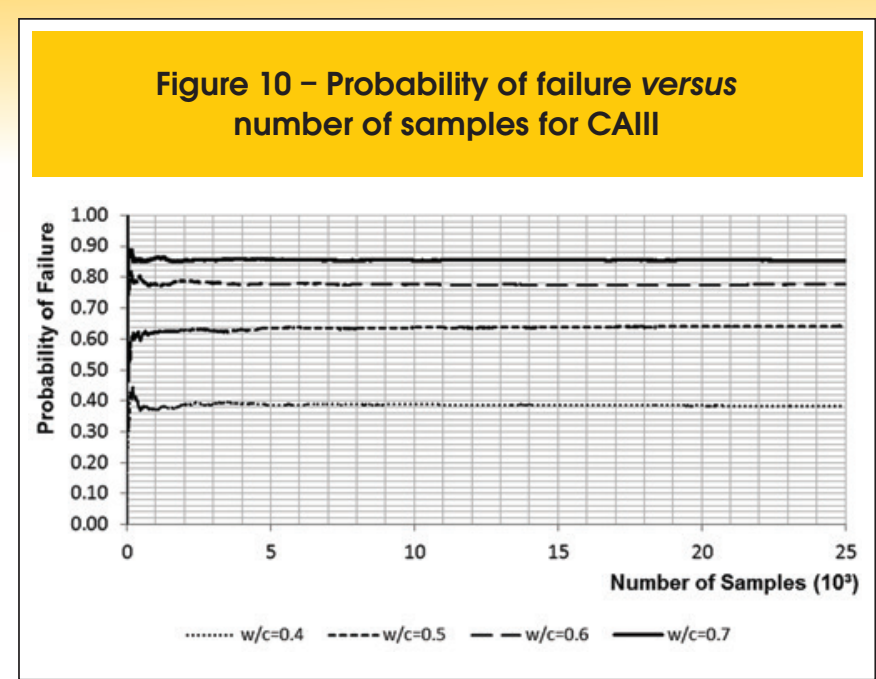

major influence on the probability of corrosion initiation. As shown in Figure 10, the change in the environmental aggressiveness significantly increases the probability of failure. For instance, when the structural element is located in a CA III environment, with a w/c ratio of 0.7 , the probability of failure reaches 0.85 .

The initiation and propagation periods were also studied assuming the mean values for all random variables that influence the corrosion process, i.e., $\left[C(x, t), D_{0}, C=x\right]$. Figures 11,13 and 15 show the results obtained when the analysed beam is located in a CA II environment. The initiation and propagation periods were determined based on the following design configurations: $\beta_{x}=0.259$; $\beta_{x}=0.628$ for a single reinforcement layer; and $\beta_{x}=0.628$ for a double reinforcement layer. Different $w / c$ ratio values were adopted.
Figures 12,14 and 16 present the initiation and propagation periods, assuming CA III environmental aggressiveness.

The results presented in Figures 11-16 indicate the direct influence of the w/c ratio and the chloride concentrations at the structural surface on the reinforcement depassivation.

As observed in previous results, the propagation period for CA II is considerably shorter than the initiation period. Therefore, for this environmental aggressiveness class, the initiation period should be used to evaluate durability.

However, for CA III and high w/c ratios, the opposite behaviour is observed. This behaviour is expected because more porous concrete has larger $w / c$ ratios and the ingress of chloride is easier. When large w/c ratios are considered and the environment is aggressive, the initiation period is short compared to the propagation period. According to [4] and [9], the larger the w/c ratio, the less severe the corrosion rate. This is another factor that reduced the initiation period in this analysis. However, the structural lifetime (initiation and propagation periods together) for CA III is considerable shorter than for the CA II scenario.

Therefore, it can be concluded that for concretes with a low w/c ratio, the initiation period is larger than the propagation period. For concretes with a high w/c ratio, the initiation period is shorter than the propagation period. The durability, i.e., the sum of the initiation and propagation periods, is higher for concretes with a low w/c ratio.

\subsection{Example 3}

In this example, the reinforced concrete beam was analysed considering the following strain domains: $\beta_{x}=0.259 ; \beta_{x}=0.628$ for $a$ single reinforcement layer; and $\beta_{x}=0.628$ for a double reinforcement layer to evaluate the probability of structural failure resulting from the loss of structural resistance because of reinforcement

Figure 11 - Initiation and propagation periods considering CA II and $\beta \mathrm{X}=0.259$
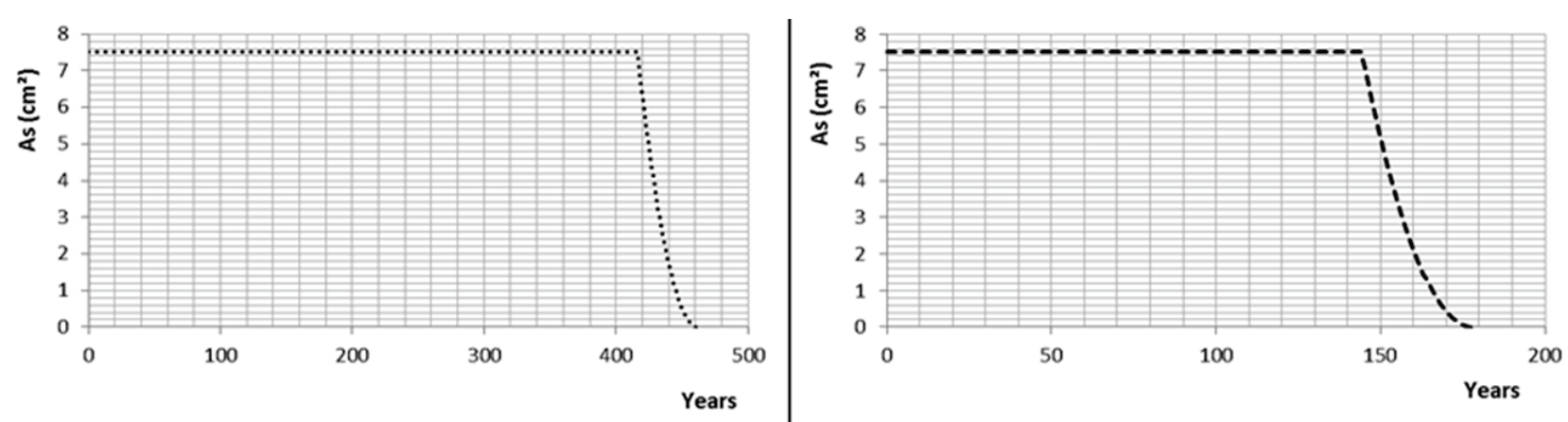

$\cdots \cdots \times / c=0.4$
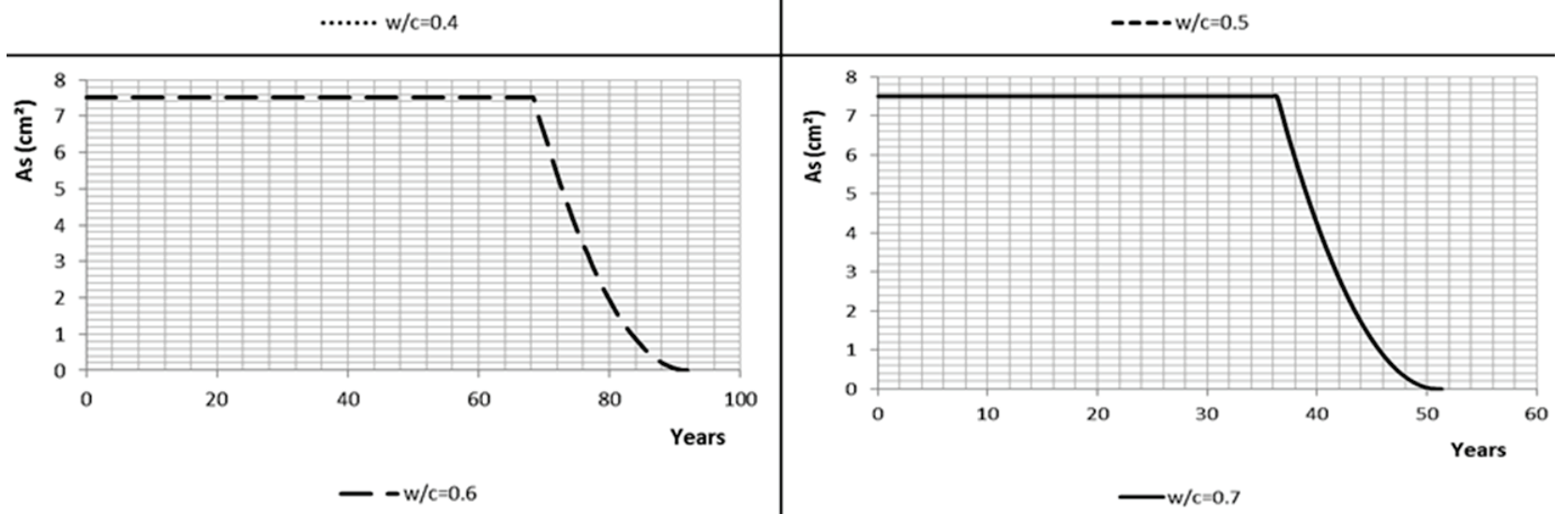


\section{Figure 12 - Initiation and propagation periods considering CA III and $\beta X=0.259$}
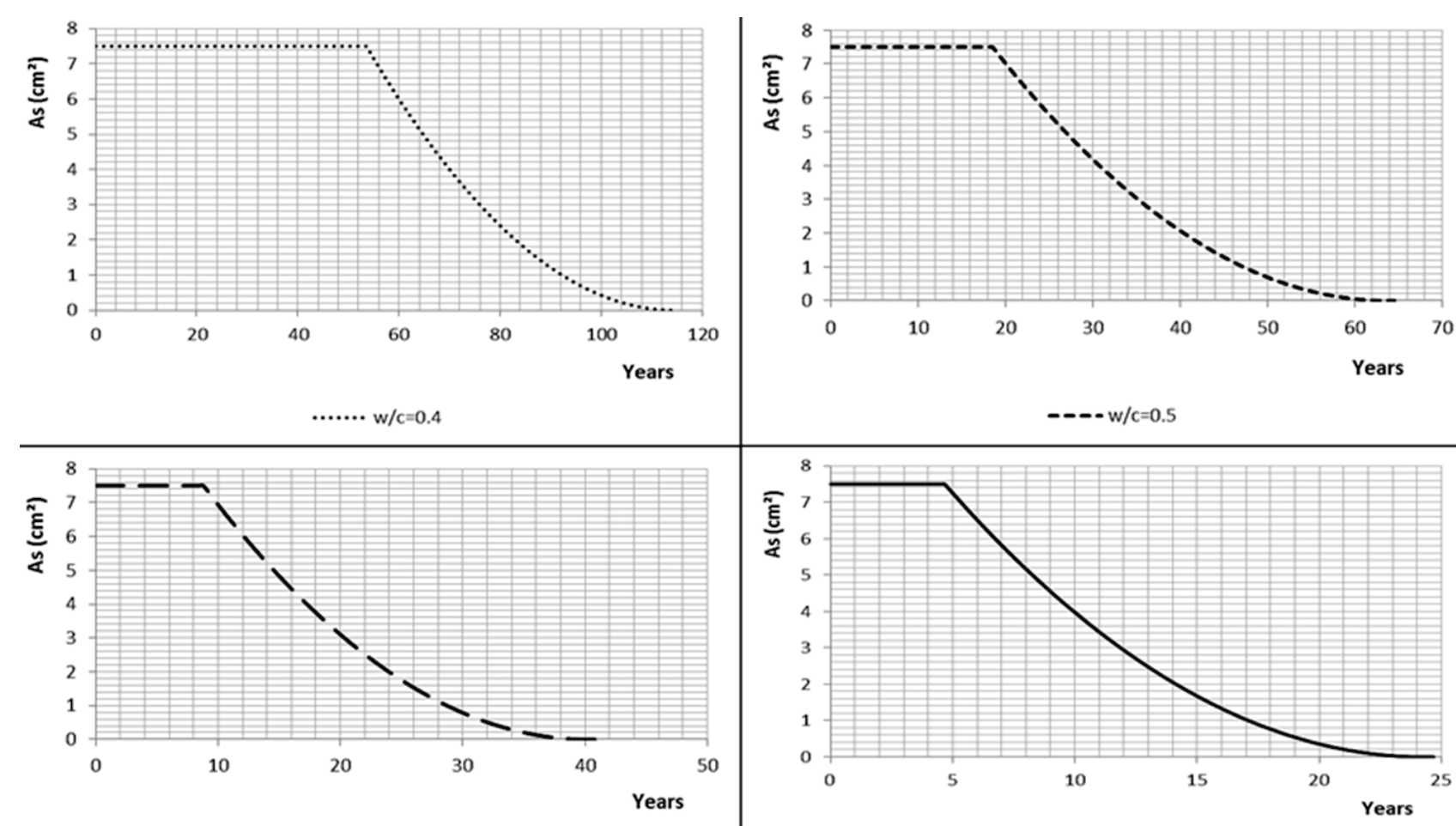

$--\mathrm{w} / \mathrm{c}=0.6$

$-\mathrm{w} / \mathrm{c}=0.7$

Figure 13 - Initiation and propagation periods considering CA II and $\beta \mathrm{X}=0.628$ single reinforcements' layer
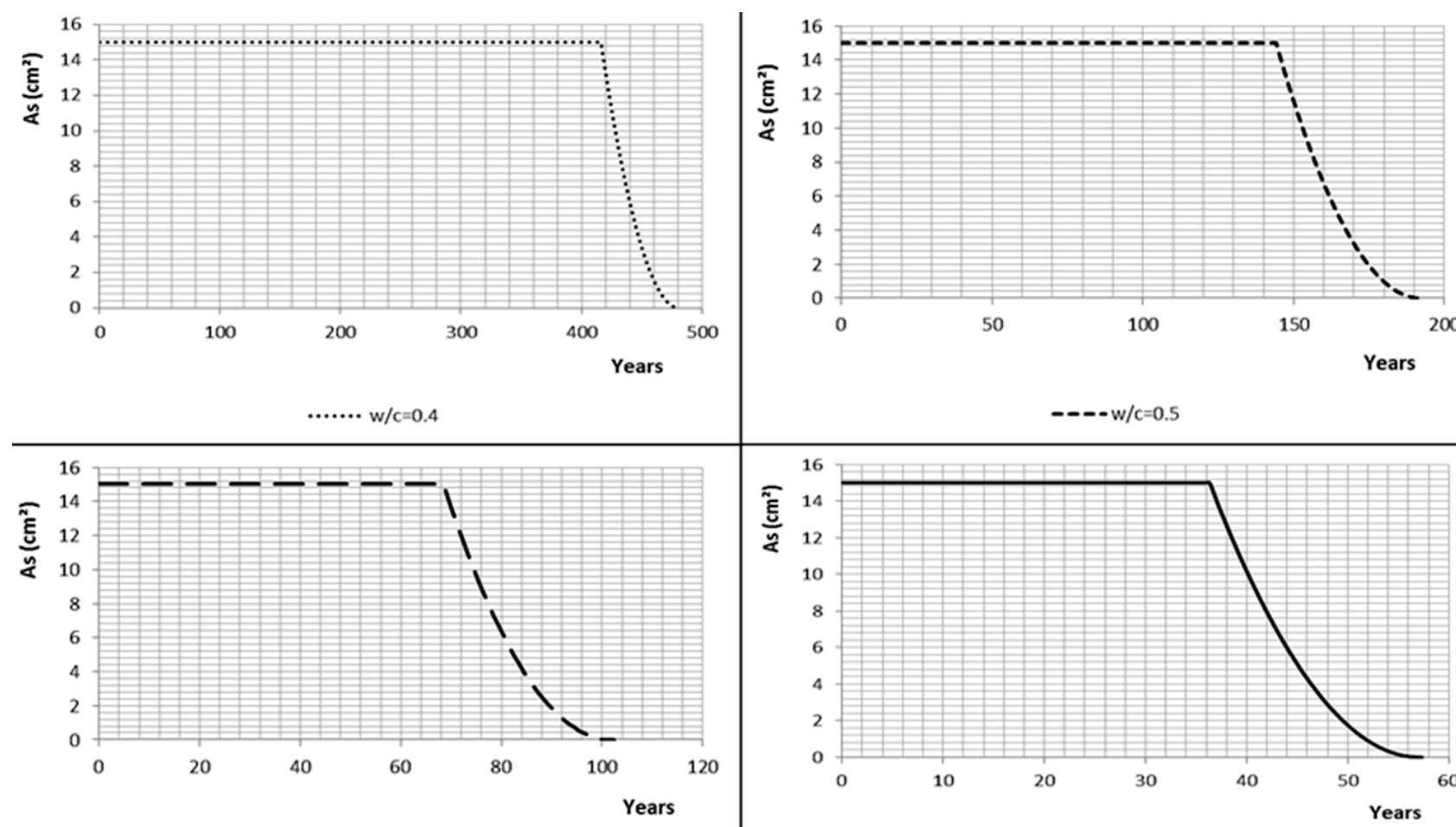

$--\mathrm{w} / \mathrm{c}=0.6$

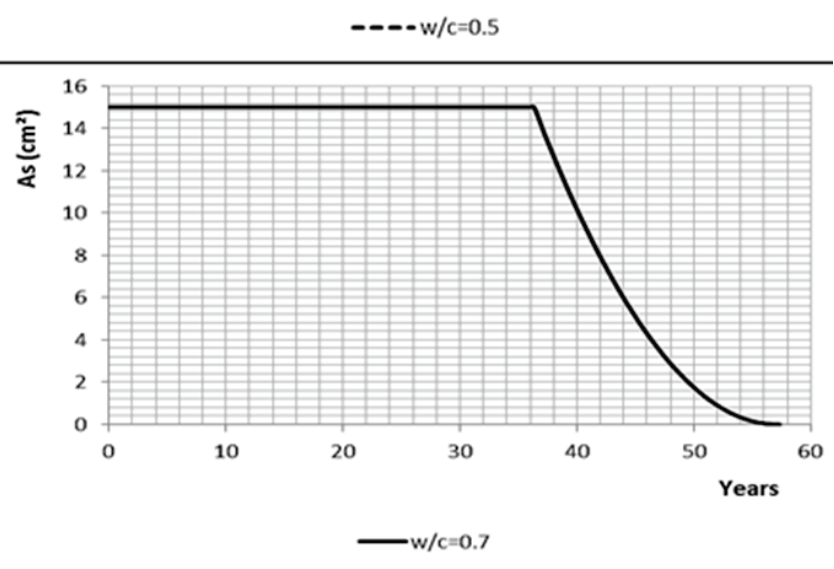


Influence of the reinforcement corrosion on the bending moment capacity of reinforced concrete beams: a structural reliability approach

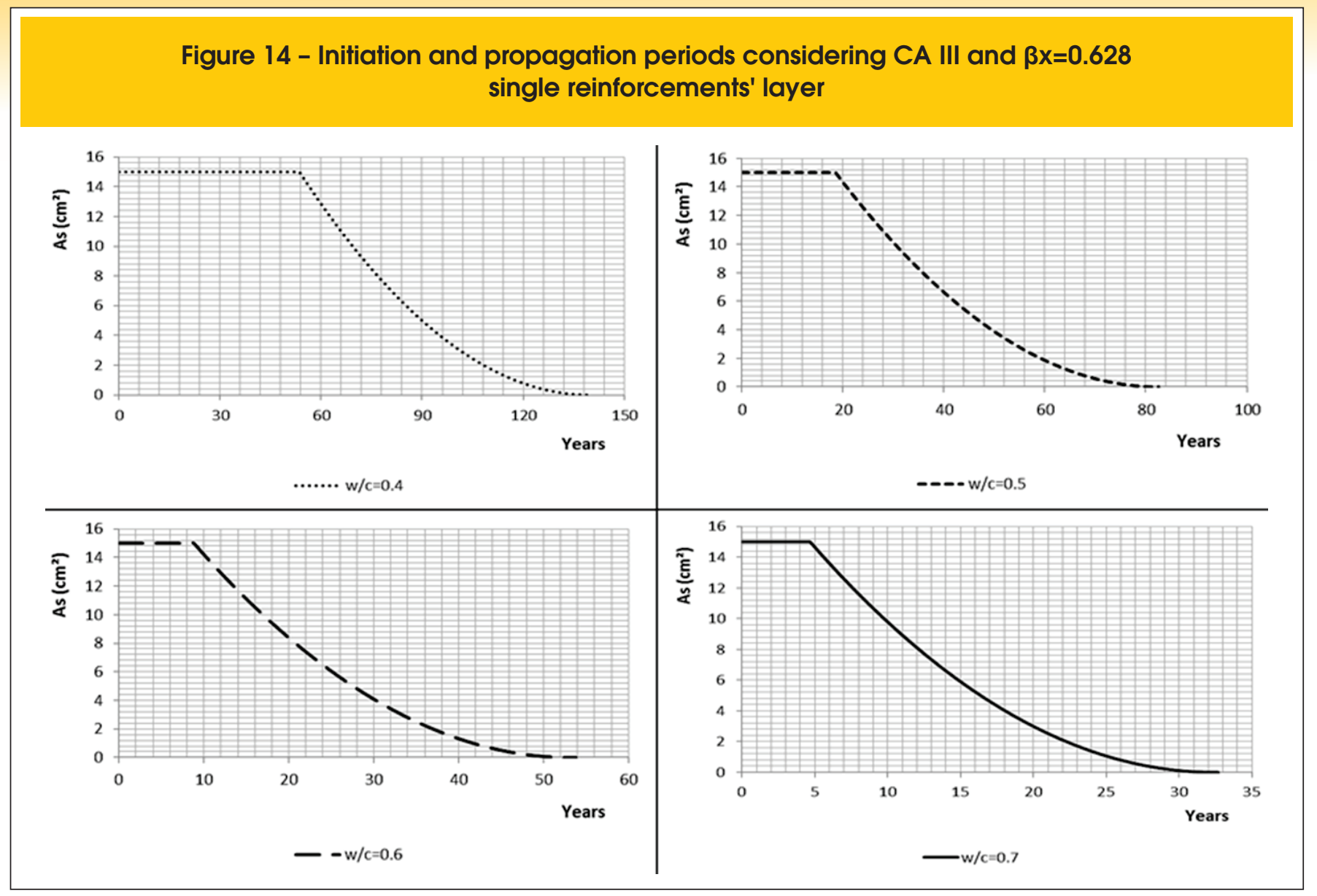

Figure 15 - Initiation and propagation periods considering CA II and $\beta X=0.628$ double reinforcements' layer
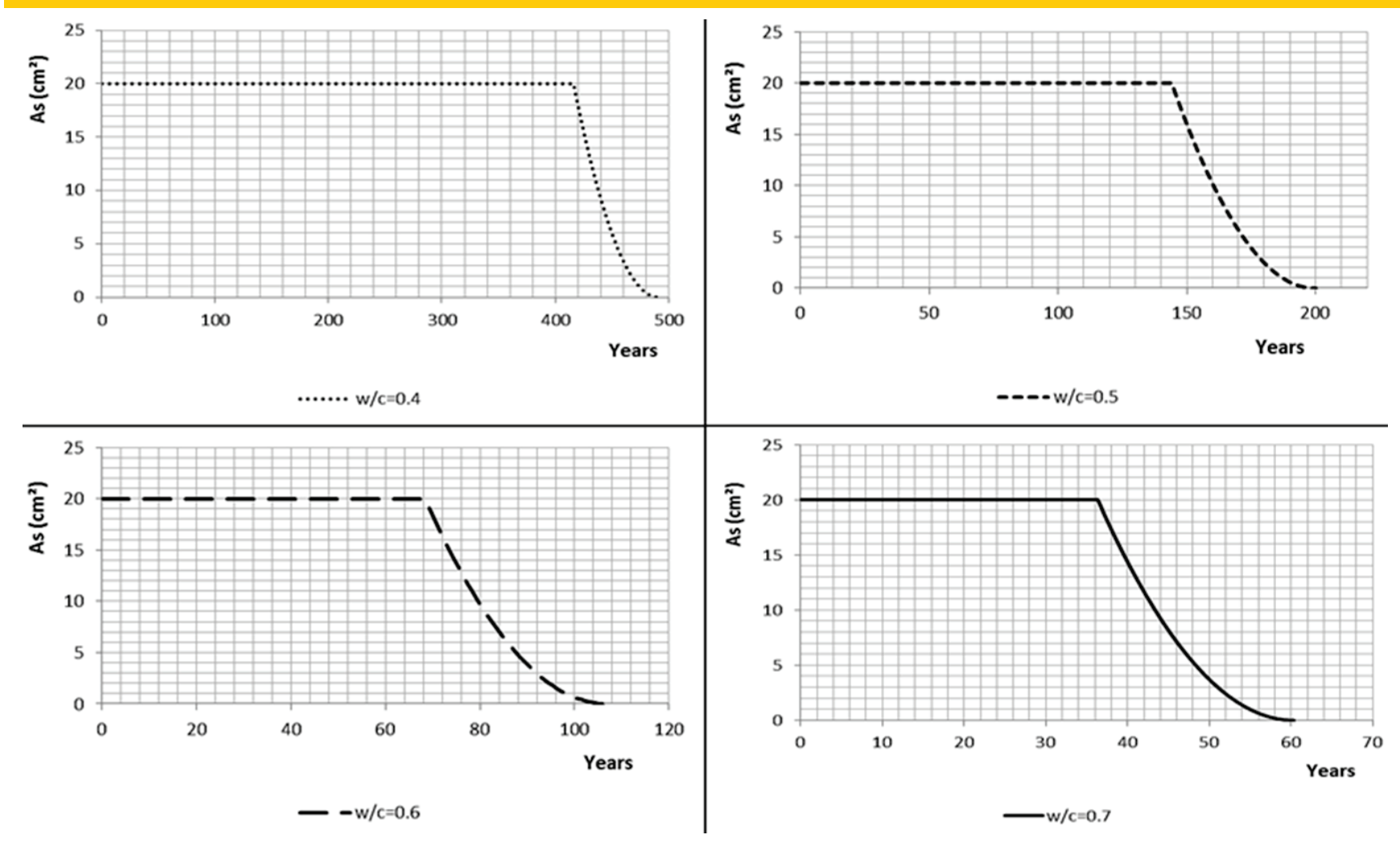
corrosion. The limit state function considered in this analysis is given by:

$\mathrm{G}_{3}=\mathrm{M}_{\mathrm{r}}-\mathrm{M}_{\mathrm{a}}$

When the initiation period finishes, the corrosion of reinforcements is considered and the reinforcement cross section deteriorates using Eq. (14). After determining the initial reinforcements cross-section from Equations (1), (3) or (4) (for beam with single or double layer reinforcement) the diameter of the corroded reinforcements is determined using Eq. (14). The probabilistic analyses were performed considering a structural lifetime equal to 30 years $\left(t_{\text {corr }}\right)$.

The corrosion rate $\left(\mathrm{i}_{\mathrm{CORR}}\right)$ was calculated using CA II (urban environment) and CA III (marine environment) and the following water/cement ratios were used: $\mathrm{w} / \mathrm{c}=0.4, \mathrm{w} / \mathrm{c}=0.5, \mathrm{w} / \mathrm{c}=0.6$ and $w / c=0.7$.

After determining the diameter of the corroded reinforcements, the neutral surface within the beam cross-section and the reinforcement areas were updated and the resistant bending moment was evaluated using Eq. (8).

The probabilistic analyses were performed using Monte Carlo simulations with 500,000 samples for each random variable. The results are shown in Figures 17-22. These figures illustrate the probability of structural failure over time considering two aggressive environments, three strain domains and four water/cement ratios. Based on the results, the probabilities of failure of $0.003,0.005$ and 0.004 calculated for the strain domains of $\beta_{x}=0.259, \beta_{x}=0.628$ for single reinforcement layer and $\beta_{x}=0.628$ for double reinforce- ment layer, respectively, remained constant from construction until reinforcement depassivation, which was expected. After the reinforcement depassivation, the probabilities of failure increased significantly for all $\mathrm{w} / \mathrm{c}$ ratio values considered.

As observed in Figures 18, 20 and 22, high environmental aggressiveness (CA III) triggered earlier corrosion of the reinforcements.

\section{Conclusions}

The results from the studied examples indicate that the design procedures presented in [1] result in a safe structural level. The calculated probabilities of failure are in the range $10^{-3}-10^{-4}$, which is acceptable according to [25].

The start of reinforcement corrosion depends on several factors. Of particular importance are the chloride concentration at the structural surface, which is associated with an aggressive environment, and the water/cement ratio, which reflects the porosity of the material. The chloride ingress increases with the porosity of the material.

The durability of reinforced concrete structures should be associated with more accurate cover thickness and water/cement ratio values. By specifying more accurate concrete cover values, the chloride ingress and its concentration over time are improved, delaying reinforcement corrosion. The probabilistic approach, considering the inherent randomness of the variables that influence this mechanical problem, has proven adequate for determining the times for corrosion initiation and reinforcement cross-section deterioration.

Finally, the results presented on this paper inspire studies aiming to consider maintenance and reparation procedures assuming the more probable time of structural failure. This study is due

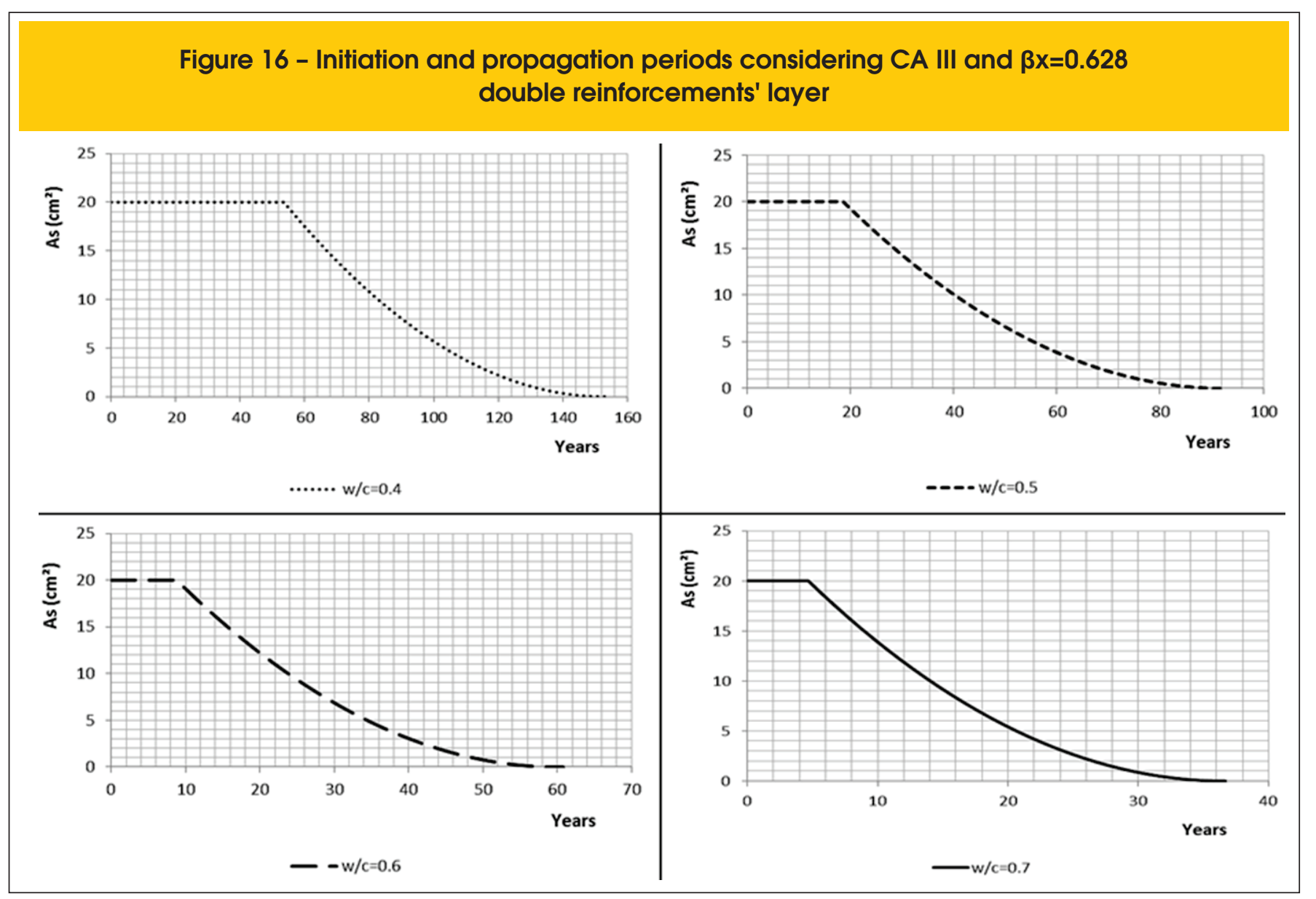


in course by the research group headed by the senior author of this paper.

\section{Acknowledgements}

Sponsorship of this research project by CAPES is greatly appreciated. This research is a part of the activities scheduled by the research project USP/COFECUB 2012.1.672.1.0.

\section{References}

[01] ASSOCIAÇÃO BRASILEIRA DE NORMAS TÉCNICAS. ABNT NBR 6118: Projeto de estruturas de concreto - procedimento. Rio de Janeiro, 2003.

[02] MEHTA, P.; MONTEIRO, P.J. Concrete: Microstructure, Properties and Materials, Third edition, McGraw Hill, 2006.

[03] BICZÓK, I. Corrosión y protección del hormigón. España: Urmo S. A. De Ediciones, 1972.

[04] VU, K.A.T.; STEWART, M.G. Structural reliability of concrete bridges including improved chloride-induced corrosion models. Structural Safety, v.22, p.313-333, 2000.

[05] NOGUEIRA, C.G.; LEONEL, E.D.; CODA, H.B. Reliability algorithms applied to reinforced concrete structures durability assessment. Revista IBRACON de Estruturas e Materiais, v.5, 440-450, 2012.

[06] NOGUEIRA, C.G.; LEONEL, E.D. Probabilistic models applied to safety assessment of reinforced concrete structures subjected to chloride ingress. Engineering Failure Analysis, v.31, p.76-89, 2013.

[07] JUNG, W.Y.; YOON, Y.S.; SOHN, Y.M.Predicting the remaining service life of land concrete by steel corrosion. Cement and concrete research, v.33, p.663-677, 2003.
[08] KONG, J.S.; ABABNEH, A.N.; FRANGOPOL, D.M.; XI, Y.P. Reliability analysis of chloride penetration in saturated concrete. Probabilistic Engineering Mechanics, v.17, p.305-315, 2002.

[09] NOGUEIRA, C.G.; LEONEL, E.D.; CODA, H.B. Probabilistic failure modelling of reinforced concrete structures subjected to chloride penetration. International Journal of Advanced Structural Engineering, v.4, p.10, 2012.

[10] VAL, D.V.; STEWART, M.G. Life-cycle cost analysis of reinforced concrete structures in marine environments. Structural Safety, v.25, p.343-362, 2003.

[11] BASTIDAS-ARTEAGA, E.; CHATEAUNEUF, A.; SÁNCHEZSILVA, M.; BRESSOLETTE, P.; SCHOEFS, F. A comprehensive probabilistic model of chloride ingress in unsaturated concrete. Engineering Structures, v.51, p.259-266, 2011.

[12] EL-HASSAN, J.; BRESSOLETTE, P.; CHATEAUNEUF, A.; EL TAWIL, K. Reliability-based assessment of the effect of climatic conditions on the corrosion of RC structures subjected to chloride ingress. Engineering Structures, v.32, p.32793287, 2010.

[13] LEONEL, E.D.; BECK, A.T.; VENTURINI, W.S. On the performance of response surface and direct coupling approaches in solution of random crack propagation problems. Structural Safety, v.33, p.261-274, 2011.

[14] DURACRETE. Statistical quantification of the variables in the limit state functions. The European Union Brite EuRam 3 contract BRPR-CT95-0132 Project BE95-1347, Report BE95-1347/R7, May, 2000.

[15] CRANCK, J. The mathematics of diffusion, $2^{\text {nd }}$ Ed., Clarendon Press, Oxford, London. 414 p, 1975.

[16] DHIR, R.K.; JONES, M.R.; NG, S.L.D. Prediction of total chloride content profile and concentration/time-dependent

\section{Figura 17 - Probability of failure along time for CA II and $\beta X=0.259$}
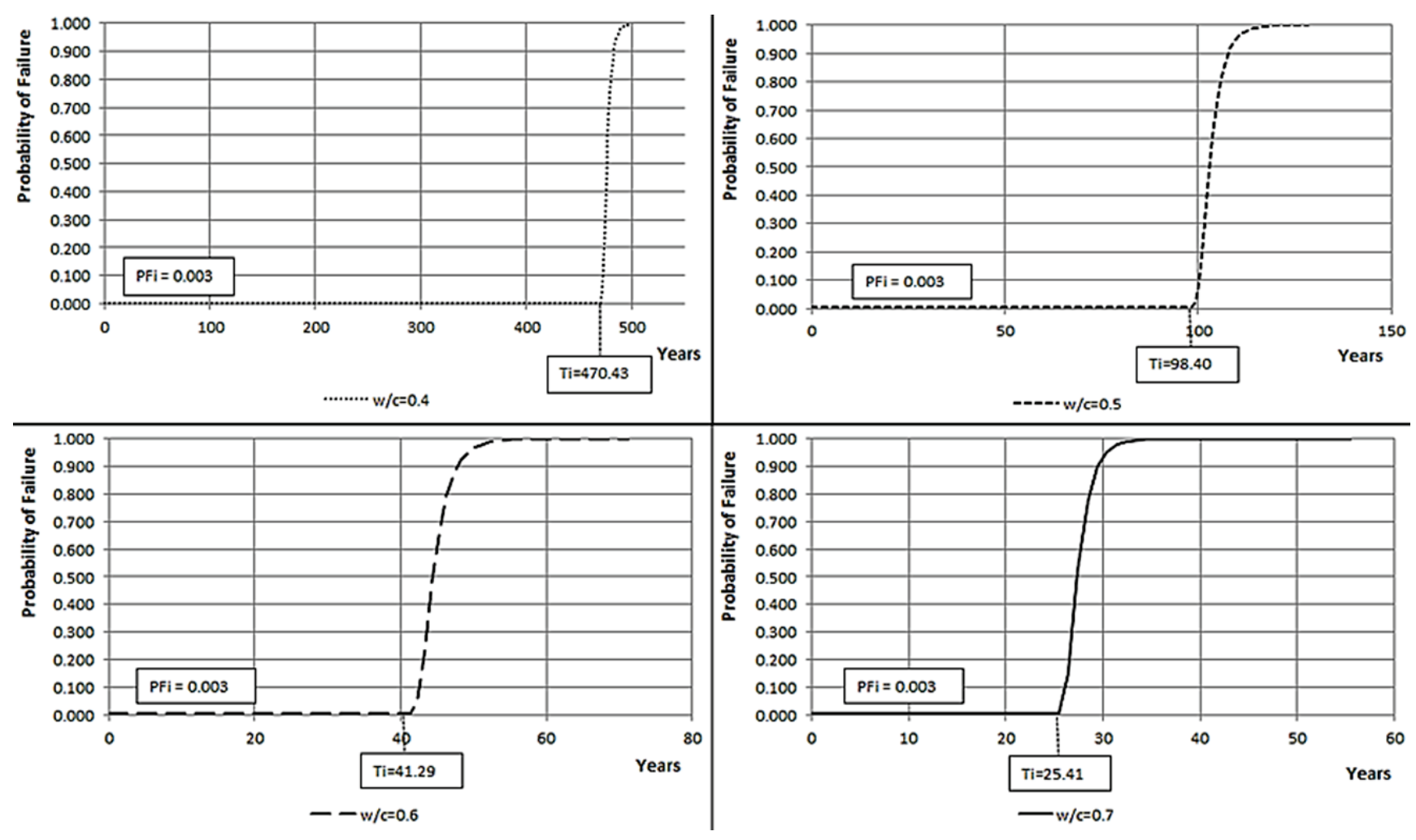
Figure 18 - Probability of failure along time for CA III and $\beta X=0.259$
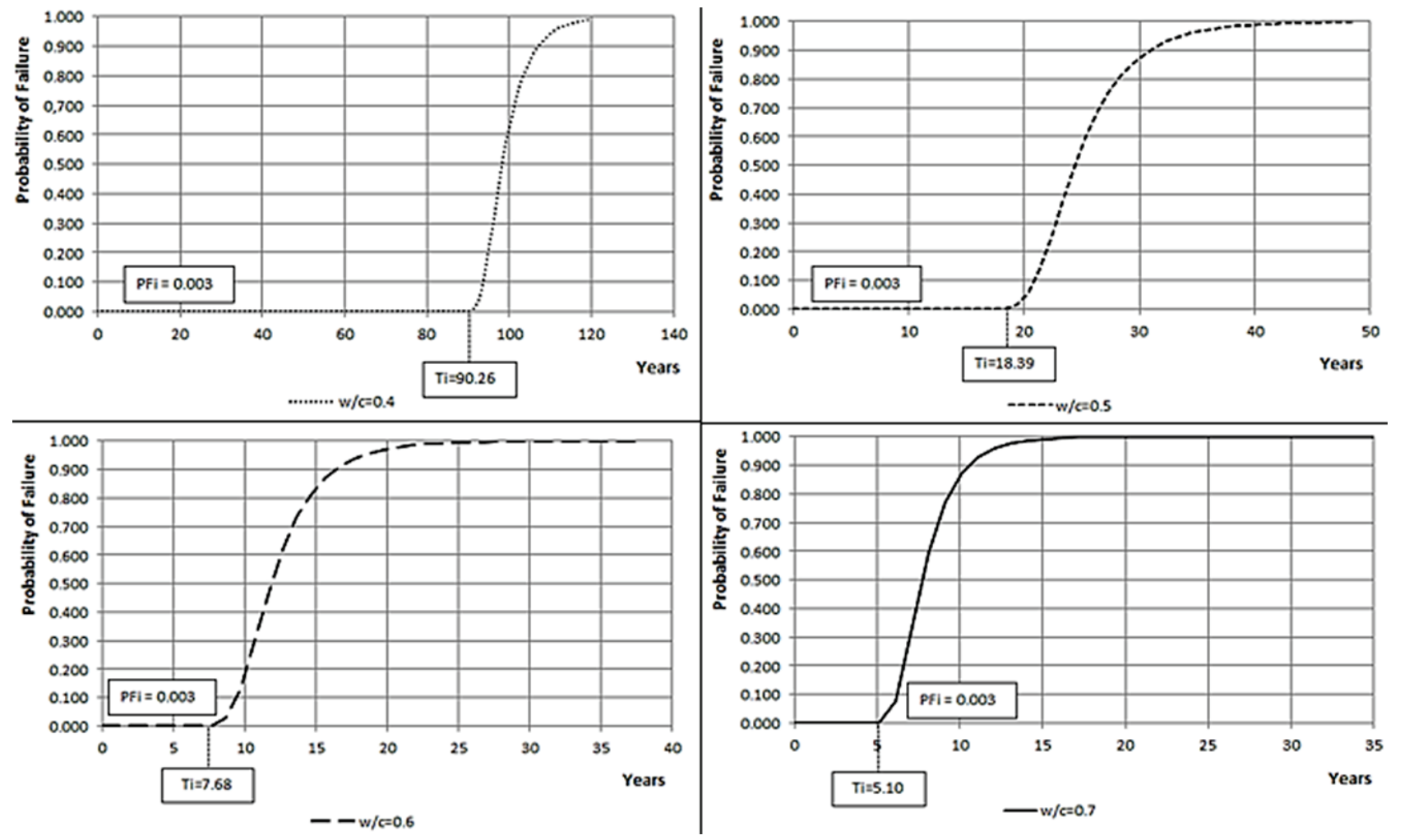

Figure 19 - Probability of failure along time for CA II and $\beta x=0.628$ single reinforcements' layer
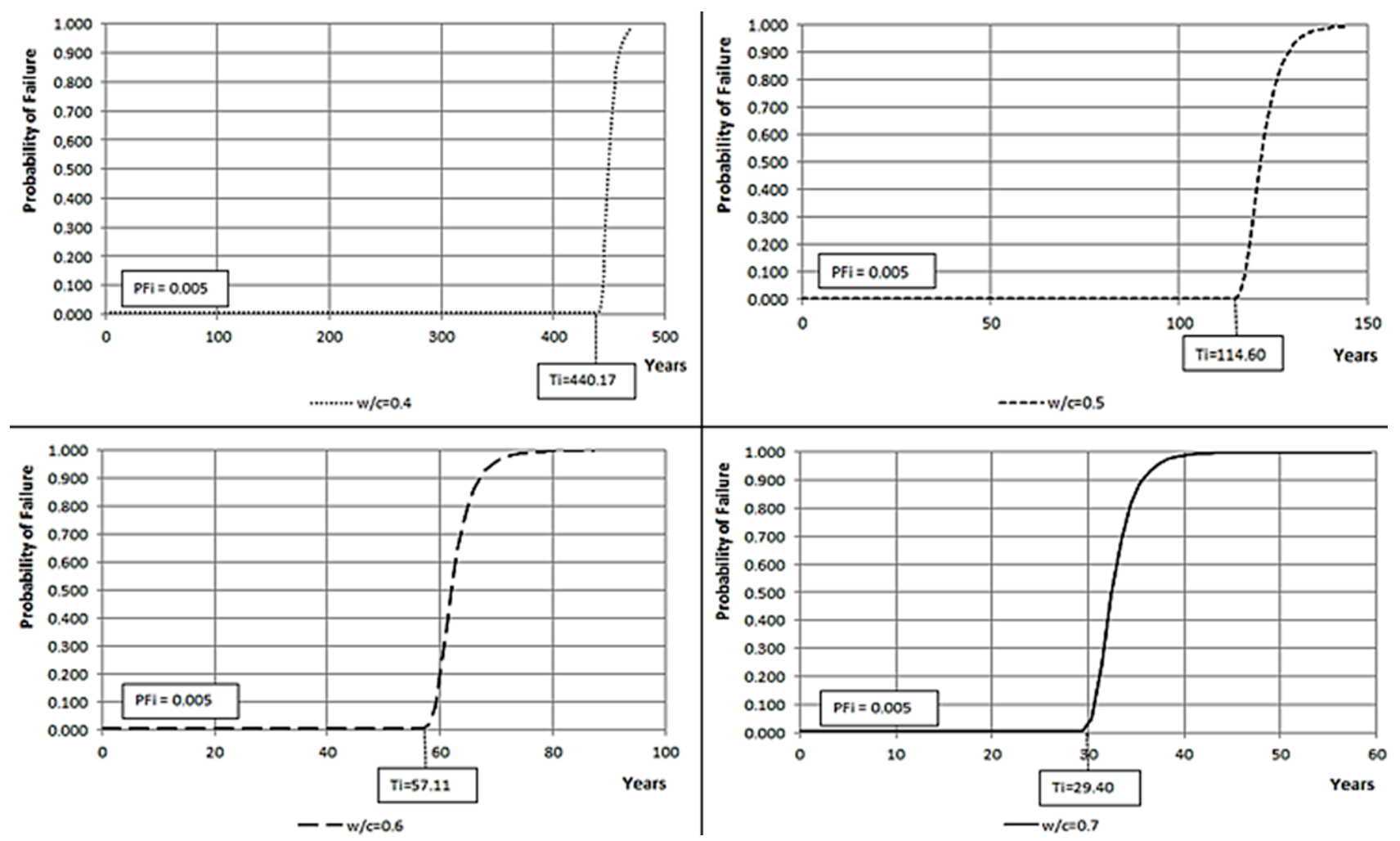
Influence of the reinforcement corrosion on the bending moment capacity of reinforced concrete beams: a structural reliability approach

Figure 20 - Probability of failure along time for CA III and $\beta x=0.628$ single reinforcements' layer
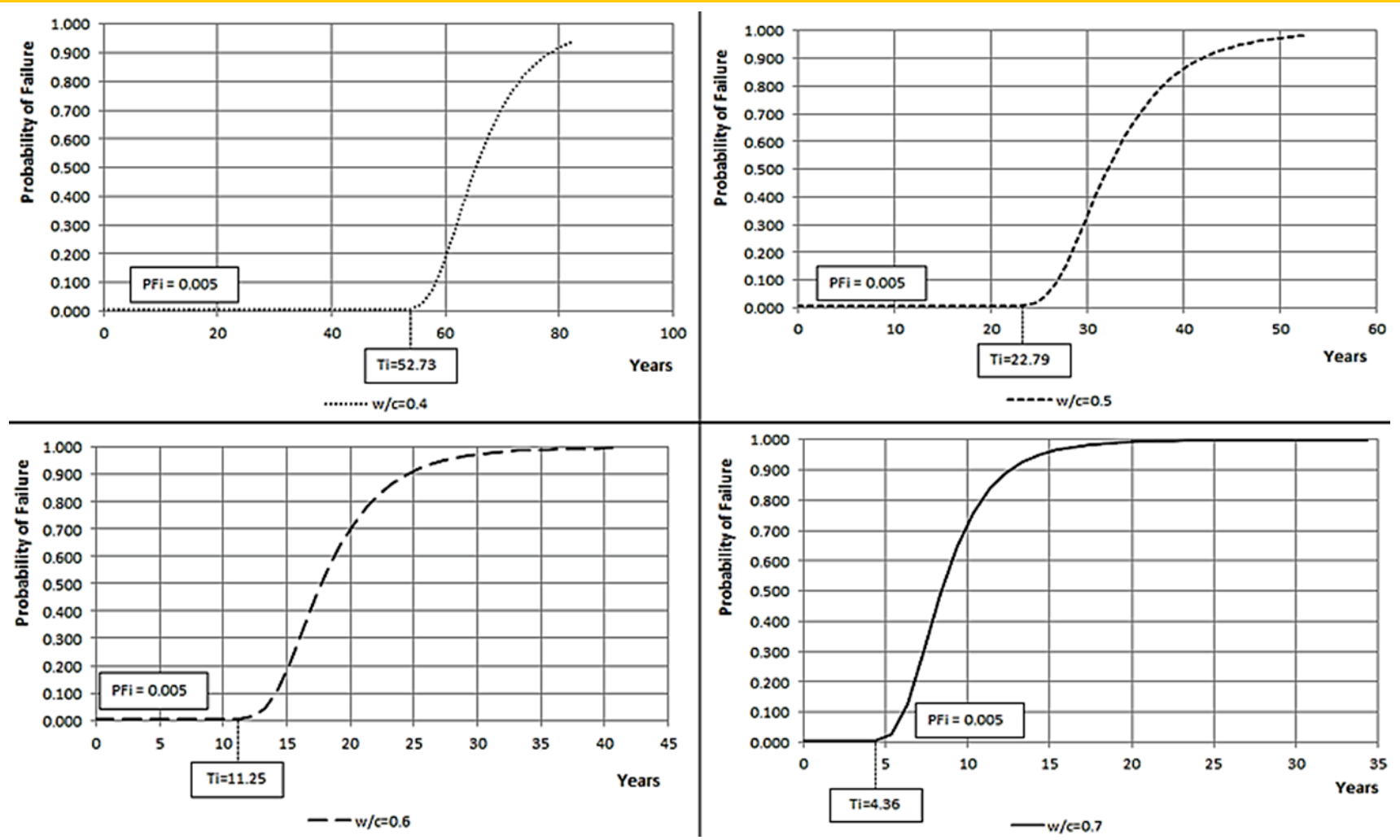

Figure 21 - Probability of failure along time for CA II and $\beta X=0.628$ double reinforcements' layer
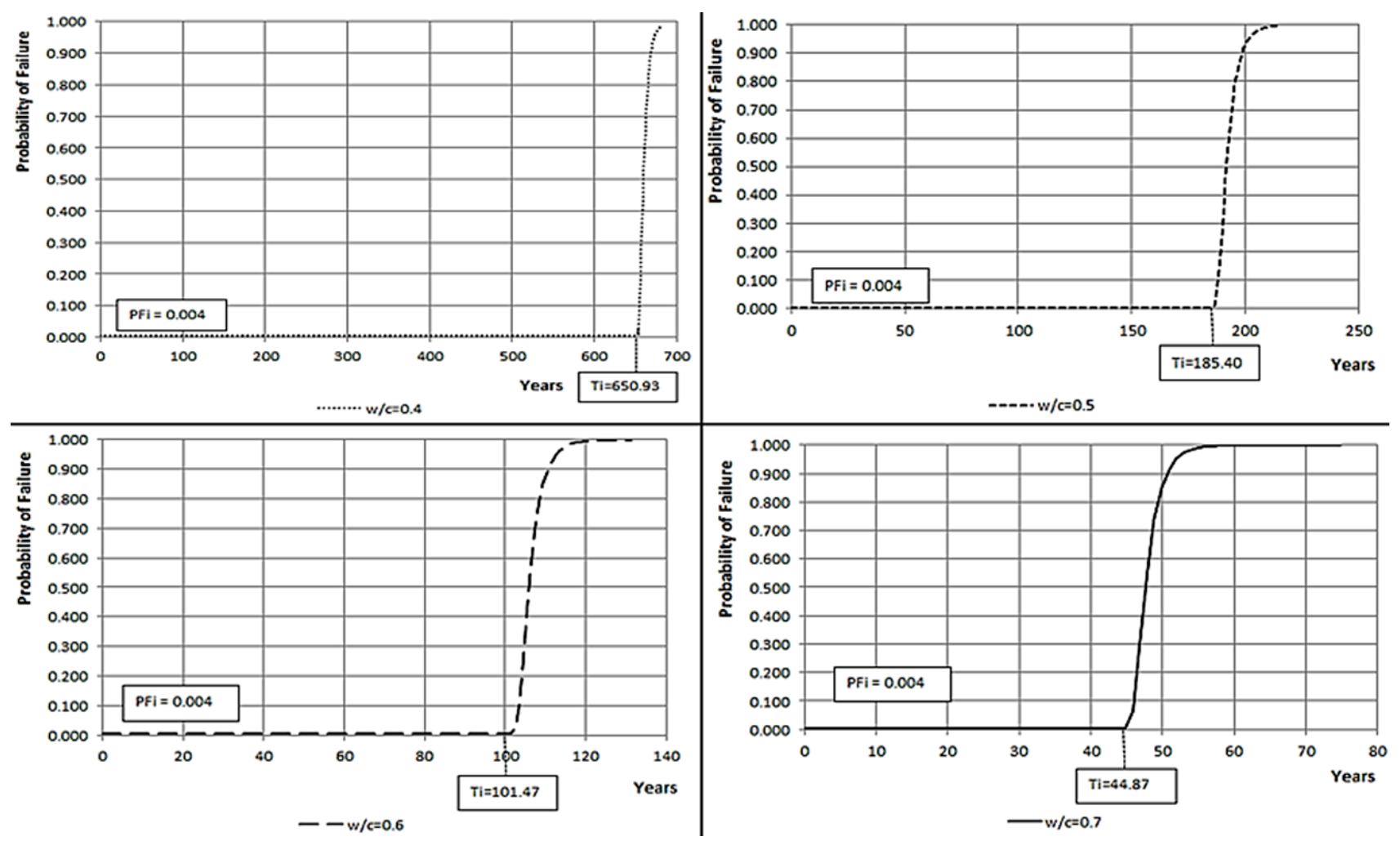
diffusion coefficients for concrete, Magazine of Concrete Research, 50:37-48, 1998.

[17] TUUTTI, K. Corrosion of steel in concrete Swedish. Cement and Concrete Research Institute Stockholm, 1982.

[18] GENTIL, V. Corrosão. 4. ed. Rio de Janeiro: LTC, 2003.

[19] CASCUDO, O. O controle da corrosão de armaduras em concreto: inspeção e técnicas eletroquímicas. São Paulo: Pini; Goiânia: Editora UFG, 1997.

[20] BASTIDAS-ARTEAGA, E.; SCHOEFS, F.; STEWART, M.G.; WANG, $X$. Influence of global warming on durability of corroding RC structures: A probabilistic approach. Engineering Structures, v.51, p.259-266, 2013.

[21] DITLEVSEN, O.; MADSEN, H.O. Structural reliability method, New York: John Wiley and Sons, 1996.
[22] HASOFER, A.M.; LIND, N.C. Exact and invariant second moment code format. Journal of the Engineering Mechanics Division, ASCE. 100 (EM1): p.111-121, 1974.

[23] NOWAK, A.S.; COLLINS, K.R. Reliability of structures. McGraw Hill, Michigan, 2000.

[24] PAPADAKIS, V.G.; ROUMELIOTIS, A.P.; FARDIS, M.N.; VAGENAS, C.G. Mathematical modeling of chloride effect on concrete durability and protection measures. In Dhir, R.K., Jones, M.R., editors. Concrete repair, rehabilitation and protection. London, E\&FN Spon, 1996.

[25] EUROPEAN COMMITTEE FOR STANDARDIZATION, STANDARD EN 1992-1-1:2004, Eurocode 2: Design of Concrete Structures - Part 1-1: General rules and rules for buildings. Brussels, 2004.

\section{Figure 22 - Probability of failure along time for CA II and $\beta x=0.628$ double reinforcements' layer}
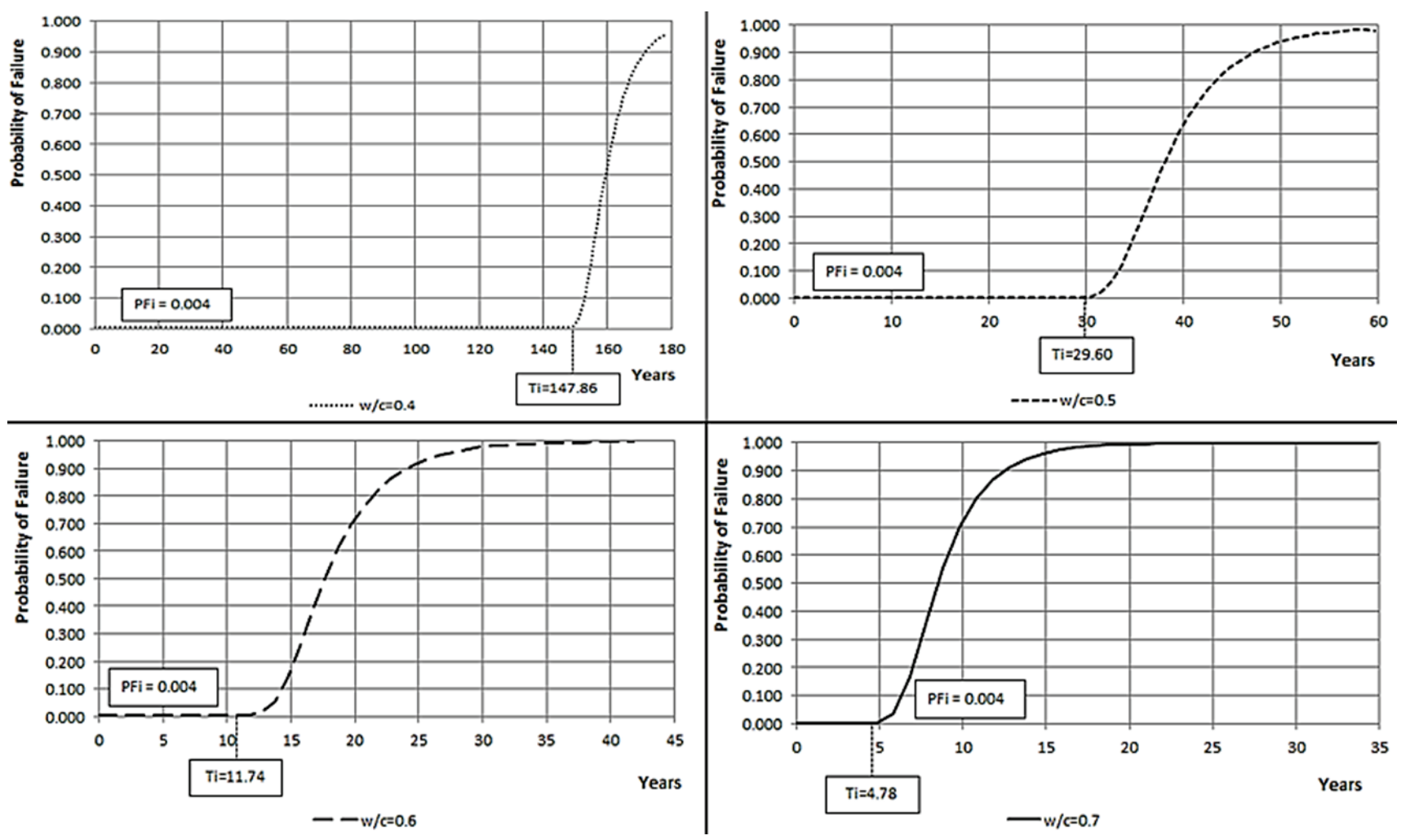